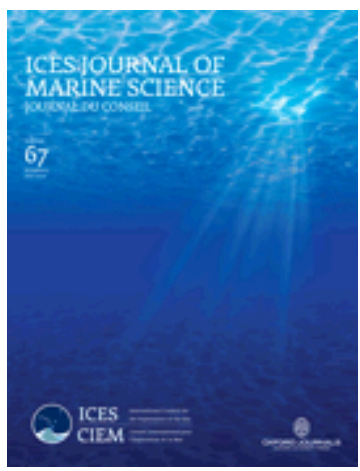

\title{
Genome-wide SNP based population structure in European hake reveals the need for harmonizing biological and management units
}

\begin{tabular}{|c|c|}
\hline Journal: & ICES Journal of Marine Science \\
\hline Manuscript ID & ICESJMS-2019-196.R2 \\
\hline Manuscript Types: & Original Article \\
\hline $\begin{array}{r}\text { Date Submitted by the } \\
\text { Author: }\end{array}$ & 16-Jul-2019 \\
\hline Complete List of Authors: & $\begin{array}{l}\text { Leone, Agostino } \\
\text { Alvarez, Paula; AZTI Tecnalia, } \\
\text { Garcia, Dorleta; Azti, } \\
\text { Saborido-Rey, Fran; Instituto de Investigaciones Marinas (CSIC), } \\
\text { Fisheries } \\
\text { Rodriguez-Ezpeleta, Naiara; AZTI, marine research division; AZTI }\end{array}$ \\
\hline Keyword: & $\begin{array}{l}\text { RAD-seq, SNP, stock delimitation, genetic connectivity, European hake, } \\
\text { fisheries management }\end{array}$ \\
\hline
\end{tabular}

\section{SCHOLARONE ${ }^{m}$ Manuscripts}


1 Genome-wide SNP based population structure in European hake reveals the need for

2 harmonizing biological and management units

3

4 Agostino Leone ${ }^{1}$, Paula Álvarez ${ }^{1}$, Dorleta García ${ }^{1}$, Fran Saborido-Rey ${ }^{2}$, Naiara Rodriguez$5 \quad$ Ezpeleta ${ }^{1, *}$

6

$7{ }^{1}$ AZTI, Marine Research Division, Txatxarramendi ugartea z/g, 48395 Sukarrieta, Bizkaia, 8 Spain

92 IIM-CSIC, Institute of Marine Research, Eduardo Cabello 6, 36208 Vigo, Pontevedra, 10 Spain

11 * Corresponding author: tel: +34 667174 514; email: nrodriguez@azti.es

12

13

14 


\section{Abstract ( $<200$ words)}

Despite its economic importance, the population structure of the European hake, Merluccius merluccius, is unresolved, and the species is assessed based on two stocks (northern and southern) separated by the Capbreton Canyon. In order to shed light into the European hake population structure, we used Restriction site Associated DNA sequencing (RAD-seq) to discover and genotype thousands of genome-wide single nucleotide polymorphisms in more than a hundred samples. Our population genetic inferences confirm differentiation of Mediterranean and northeast Atlantic locations and reveal management relevant information within the latter. First, hake in the Norwegian Sea is genetically different from that of the rest of the locations under study and, second, samples from the eastern Bay of Biscay and the northwestern Iberian Peninsula are not genetically different. These results imply that samples from the northern stock belong to different genetic populations, and that samples belonging to locations included in the northern and southern stocks are part of a single genetically homogeneous population. Although the definition of the boundary between the northern and southern stocks and the potential need for additional stocks still requires further analyses, the mismatch between biological and management units should already be considered in further assessments of European hake.

Keywords: RAD-seq; SNPs; stock delimitation; genetic connectivity; European Hake; fisheries management 


\section{Introduction}

Determining spatiotemporal genetic variation is important for sustainable fisheries management (Hauser and Carvalho, 2008). Yet, intrinsic characteristics of marine fish such as large population sizes, high dispersal capacity and high fecundity often translate into low genetic differentiation even at interoceanic distances (Nielsen and Kenchington, 2001; Nielsen et al., 2009). This often results in a mismatch between biological and management units (Reiss et al., 2009), which can lead to reduced productivity, local reduction of populations and in extreme cases, to local population collapse (Bonfil, 2005). An example of potential mismatch between biological and management units is the European hake (Merluccius merluccius) (Reiss et al., 2009), an important commercial fish that inhabits the Northeast Atlantic Ocean and adjacent seas (Korta et al., 2015; ICES, 2018). Within the Northeast Atlantic Ocean, the European hake is managed by the International Council for the Exploration of the Sea (ICES) assuming two stocks separated by the Capbreton Canyon, the northern stock extending northward to Norway (ICES Division 3a, Sub-areas 2, 4, 6 and 7, and Divisions 8a,b,d) and the southern stock, southward to Gibraltar Strait (ICES Divisions 8c and 9a) (ICES, 2011; ICES, 2018). Yet, this separation is not based on clear biological evidences other than the assumption of the barrier effect of the Capbreton Canyon (Casey and Pereiro, 1995). Additionally, in locations from the northern stock (e.g. Bay of Biscay), the main spawning season ranges from January to March, whereas in locations from the southern stock (Galicia and Portugal), spawning occurs all year round with the presence of several other peaks in summer and autumn (Korta et al., 2015; Dominguez-Petit, 2017).

There is still no consensus on the population structure of the European hake (Roldán et al., 1998; Castillo et al., 2005; Pita et al., 2014). Studies based on otolith chemistry, which reflects where fish has been born and grown, have detected differences between samples from southern (represented by northern Portugal) and northern (represented by the Norwegian Sea and West of Scotland) stocks (Swan et al., 2006), whereas others (Tanner et al., 2012) found no significant differences between samples from the northern (represented by the Celtic Sea and the Armorican Shelf) and the southern stock (represented by samples from the Portugal and Galician Shelf). Early studies based on 
microsatellite genetic markers resulted in conflicting results. For example Lundy et al. (1999) found differentiation within the northern (e.g. Celtic Sea and Norwegian Sea) and southern (e.g. Cantabrian Sea and southern Portugal) stocks but no differentiation between the two stocks (e.g Celtic Sea and Bay of Biscay). Castillo et al. (2005) confirmed the lack of differentiation between samples from the Bay of Biscay (ICES divisions $8 c$ vs. $8 \mathrm{a}, \mathrm{b}, \mathrm{d}$ ) belonging to the two stocks but found no differentiation between the Cantabrian Sea and Portuguese coast samples (ICES divisions 8 and 9). More recent studies using microsatellites have confirmed the lack of differentiation between Bay of Biscay samples belonging to northern and southern stocks and suggested a possible differentiation of North Sea samples (Pita et al., 2011; Pita et al., 2014).

Despite the advent of High Throughput Sequencing technologies and their demonstrated potential to study population structure in marine fish (Bernatchez et al., 2017), so far only one study has applied this technique to study population connectivity in the European hake (Milano et al., 2014), and is only based on 381 single nucleotide polymorphisms (SNPs), a very low number compared to the tens of thousands used in other studies aimed at resolving population structure of marine fish (Rodríguez-Ezpeleta et al., 2016; Rodriguez-Ezpeleta et al., 2017). Milano et al. (2014) did not find differentiation between northern and southern stocks when using neutral markers but found differentiation within the southern (between Galicia and North Portugal) and within the northern (between North Sea and the other locations) stocks when using 7 outlier loci. This result was further confirmed by another study based on a subset of this dataset (Westgaard et al., 2017); yet, neutral markers did not show the differentiation observed with outlier loci, even when using a bigger sample size, meaning that additional and more powerful analyses are needed to better resolve the European hake population structure.

Here, we have discovered and genotyped genome-wide SNP markers in European hake to (i) define the population structure of this commercially important species along the Mediterranean-Norwegian gradient, (ii) investigate the possibility of seasonal genetic changes within southern stock samples, and (iii) test if the current assessment and management units and population structure of European hake coincide. In order to 
reach these goals, we generated Restriction-site-Associated DNA sequencing (RAD-seq) data from 111 European hake individuals that span four geographic areas where this species inhabits: the Norwegian Sea, the eastern Bay of Biscay, the northwestern Iberian Peninsula (including samples from both spawning seasons) and the Mediterranean Sea (Balearic Sea), enabling the opportunity to explore population genetic structure and scan for selective divergences in this species. Our study reveals a mismatch between biological populations and management units in the European hake, which should be considered in the assessment of this commercially important species.

\section{Materials and methods}

\section{Sampling, DNA extraction and RAD-seq library preparation}

European hake samples from the Mediterranean Sea, the northwestern Iberian Peninsula (southern stock), the eastern Bay of Biscay (northern stock) and the Norwegian Sea (northern stock) were obtained from scientific surveys and commercial fisheries (Figure 1; Table S1). Samples include fish in spawning and pre-spawning condition, assumed to be at or close to where they will spawn, and juveniles of age 0 (less than $20 \mathrm{~cm}$ ), assumed to be close to where they were born (de Pontual et al., 2013). From each specimen, a $\sim 1 \mathrm{~cm}^{3}$ muscle sample was excised and stored in $96 \%$ molecular grade ethanol at $-20^{\circ} \mathrm{C}$ prior to DNA extraction. Genomic DNA was extracted from about $20 \mathrm{mg}$ of muscle tissue using the Wizard ${ }^{\circledR}$ Genomic DNA Purification kit (Promega, WI, USA) following manufacturer's instructions. Extracted DNA was suspended in Milli-Q water and concentration was determined with the Quant-iT dsDNA HS assay kit using a Qubit $^{\circledR} 2.0$ Fluorometer (Life Technologies). DNA integrity was assessed by electrophoresis. RAD-seq libraries were prepared following the methods of Etter et al. (2011). Between 300 and 400 ng of genomic DNA per sample was digested using the SbfI restriction enzyme and then ligated to modified Illumina P1 adapters containing 5bp sample-specific barcodes. Pools of 32 DNA samples were sheared using the Covaris ${ }^{\circledR}$ M220 Focused-ultrasonicator ${ }^{\mathrm{TM}}$ Instrument (Life Technologies) and size-selected to 300 $500 \mathrm{pb}$ by cutting DNA fragments migrated though an agarose gel. Following the ligation 
137 of the Illumina P2 adaptors, each genomic library was amplified using 12 PCR cycles.

138 Finally, the pools were paired-end sequenced (100 bp) on an Illumina HiSeq2000.

139

140

141

142

143

144

145

146

147

148

149

150

151

152

153

154

155

156

157

158

159

160

161

162

163

164

165

166

167

168

\section{RAD-tag assembly and SNP calling}

Generated RAD-tags were analyzed using Stacks version 2.1 (Catchen et al., 2013). Quality filtering and demultiplexing was performed using the Stacks module process_radtags, truncating all reads to 90 nucleotides after sequence quality verification in FastQC (Andrews, 2010) in order to avoid lower quality bases at the end of the read. The module clone filter was applied to reads whose forward and reverse pairs passed quality filtering to remove PCR duplicates, and only samples with at least 400,000 clone and quality-filtered reads remaining were kept. The module ustacks was then used to assemble orthologous tags (stacks) per individual, with a minimum coverage depth required to create a stack (parameter $-m$ ) of 5 , and a maximum nucleotide mismatches allowed between stacks (parameter $-M$ ) of 2. RAD loci were then assembled using the module cstacks with a maximum of 2 mismatches allowed between sample tags when generating the catalog (parameter $-n$ ). Matches to the catalog for each sample were searched using sstacks. The module populations was used to export from the catalog the SNPs present in RAD loci found in at least $75 \%$ of the individuals. The software PLINK version 1.07 (Purcell et al., 2007) was used to further filter the data. The initial filtering steps were based on a maximum of $10 \%$ of missing values per locus, and a maximum of $25 \%$ of missing values per individual. Subsequently, SNPs with a minimum allele frequency (MAF) smaller than 0.05 and which failed the Hardy Weinberg equilibrium (HWE) test at $p<0.05$ in at least two areas of study were excluded from downstream analyses. Only the first filtered SNP of each RAD-tag was kept. Additionally, an alternative dataset with $M=4$ and $n=6$ (keeping the rest of the parameters unchanged) and another with MAF threshold of 0.1 (keeping the rest of the parameters unchanged) were also explored for consistency as suggested (Díaz-Arce and RodríguezEzpeleta, 2019). The genotype files are available at $X$ [to be added upon acceptance].

Identification of outlier loci 
169 Outlier loci, potentially under selection, were identified using the independent 170 approaches used by Bayescan version 2.0 (Foll and Gaggiotti, 2008) and Arlequin version 171 3.5.2.2 (Excoffier and Lischer, 2010) using the whole dataset and only the Bay of Biscay 172 (Western and Eastern) samples. In Bayescan, 20 pilot runs of 5,000 iterations each were run, with a burn-in of 50,000 iterations, 5,000 samples with a thinning interval of 10 and a prior odd increased to 100 in order to minimize potentially false positives in a dataset with $>10,000$ loci. Using these parameters, loci with an $\alpha$-value significantly $>0$

\section{Genetic diversity and structure analyses}

Analyses where performed on the whole SNP dataset, on the neutral SNP dataset and on the outlier SNP dataset. Expected and observed heterozygosity per group (He and Ho respectively), pairwise average FST among groups and distributions of FST and FIS values were computed with Arlequin version 3.5.2.2 (Excoffier and Lischer, 2010). Principal component analyses (PCA) and a three-cluster based discriminant analyses of principal components (DAPC) (Jombart et al., 2010) were performed without any a priori assignment of individuals to populations using the package adegenet (Jombart and Ahmed, 2011) in R version 3.5.0 (R Core Team, 2018). The best number of PCs to retain for the DAPC analysis was inferred using the cross-validation test. The genetic ancestry of each individual was estimated using the admixture model as implemented in the Bayesian clustering approach in STRUCTURE version 2.3.4 (Pritchard et al., 2000) without any prior population assignment. Estimations were obtained from the 300,000 
201 iterations that followed a burn-in period of 100,000 iterations. Each value of potential

202

203

204

205

206

207

208

209

210

211

212

213

214

215

216

217

218

219

220

221

222

223

224

225

226

227

228

229

230

231 ancestral population ( $\mathrm{K}$ from 1 to 5 ) was examined with CLUMPP (Jakobsson and Rosenberg, 2007) to identify common modes, and results were plotted using DISTRUCT (Rosenberg, 2004). The value of $\mathrm{K}$ that better fits the data was identified according to the Evanno method (Evanno et al., 2005) as implemented in StructureHarvester (Earl and vonHoldt, 2012). Additionally, ten subsets of 300 randomly selected SNPs were analyzed with $\mathrm{K}=3$ in order to investigate the effect of using a smaller dataset of genomewide representative SNPs.

\section{Results}

SNP datasets

Of the 111 analyzed samples, only one was removed for having too few reads. Considering the remaining samples, between 402599 and 3053042 quality-filtered RAD-tags per individual were obtained (average of 1365 352). Ninety percent of the reads were used to build the stacks, with a range per individual between $81 \%$ and $95 \%$, and the average effective per-sample coverage is $34.1 x$ (stdev $=12.8 x, \min =11.3 x$, $\max =72.9 x)$. The number of RAD-loci present in at least $75 \%$ of the individuals was 29 090, totaling 452702 SNPs. After filtering for missing data, minor allele frequency and Hardy-Weinberg equilibrium and keeping a single SNP per tag, the number of RAD-loci and SNPs remaining for analysis was 14120 (Figure S1). The amount of missing data was less than $5 \%$ overall, and datasets with 0 and $1 \%$ of missing data, albeit composed of fewer SNPs produced equivalent results (not shown). Of the remaining SNPs, 147 (1\% of the total) and 217 SNPs (1.5\% of the total) were considered outliers according to the Bayesian approach implemented in Bayescan and the hierarchical Fdist model implemented in Arlequin when using the whole dataset (Figure S2), and 116 of them were common to both approaches. No outlier loci were found when using only the northwestern Iberian Peninsula and the Eastern Bay of Biscay samples. Additionally, 347 SNPs ( $2.4 \%$ of the total) were considered outliers according to the multivariate approach implemented in pcadapt. Of these loci, 108 were included in the 116 shared outlier 
232

233

234

235

236

237

238

239

240

241

242

243

244

245

246

247

248

249

250

251

252

253

254

255

256

257

258

259

260

261

262

datasets by Bayescan and Arlequin. Annotation of each of the outlier SNPs is available in Table S2.

\section{Genetic diversity and population structure}

Ranges of observed and expected heterozygosity per groups were similar, both when using the whole or the only outlier SNP dataset, indicating no deficits of heterozygous genotypes in all samples (Table 1). STRUCTURE analyses using the best $K$ values according to the Evanno method for the whole or the outlier only datasets (Table S3) resulted in three well differentiated clusters: i) the Mediterranean Sea samples, ii) the northwestern Iberian Peninsula and the eastern Bay of Biscay samples and iii) the Norwegian Sea samples (Figure 2), with no further structure observed when including only the eastern Bay of Biscay and the northwestern Iberian Peninsula samples. Analyses based on higher values of $\mathrm{K}$ resulted in no further differentiation (Figure S3). Analyses based on ten subsets of 300 randomly selected SNPs datasets provided varying results (Figures S4): same differentiation pattern (five subsets), no differentiation within the Atlantic (four subsets) differentiation between the Mediterranean plus Norwegian Sea samples and the northwestern Iberian Peninsula plus the eastern Bay of Biscay samples (one subset). The Analysis of Principal Components (PCA) on the whole dataset were congruent with the STRUCTURE analyses, revealing the same three well differentiated groups (Figure 3), even with alternative RAD-tag assembly parameter and MAF threshold values (Figure S5), and with the Discriminant Analysis of Principal Component (DAPC) when using three clusters (Figure S6).

The locus-by-locus FST and FIS were distributed around zero (Figure S7) suggesting a balanced amount of heterozygosity and homozygosity along the loci, which is congruent with the low number of outliers detected. Pairwise FST values among the three differentiated areas were significant ranging from 0.023 to 0.058 , from 0.443 to 0.498 and from 0.014 to 0.042 (Table 2, S4 and S5) when using all, only the outlier SNPs and only the neutral SNPs respectively. Low and not significant differentiation was detected within samples from southern Europe, even when using only adult samples or only 
263

264

265

266

267

268

269

270

271

272

273

274

275

276

277

278

279

280

281

282

283

284

285

286

287

288

289

290

291

292

293

294

outlier SNPs suggesting that all samples from the Northern Spanish coast are part of a single population with no seasonal demographic changes.

\section{Discussion}

Genome-wide population structure of European hake does not support current stock delineation

Our genome-wide marker-based population structure inference of European hake supports differentiation between Mediterranean and Northeast Atlantic hake. Within the Northeast Atlantic, our study showed a clear differentiation between the Norwegian Sea and southern Europe, but did not find differences between samples of the Bay of Biscay and northwestern Iberian Peninsula, belonging to the northern and southern stocks. These results confirm previous findings using microsatellites that found no differentiation between samples within the Bay of Biscay and Celtic sea, but found differentiation between these regions and the Norwegian Sea (Lundy et al., 1999; Pita et al., 2014). Interestingly, the only previous study based on SNP markers (Milano et al., 2014) failed to detect population structure within the Northeast Atlantic when using neutral markers, which could be due to a lack of evolutionarily informative signal in the few (299) markers used. Yet, when we base our inferences in 300 randomly selected SNPs, we still observe population structure, but only in half of the ten subsets. This suggests that using a few selected hundreds SNPs as in previous studies (Milano et al., 2014) are not enough for a reliable inference of hake population structure. Using a small subset of outlier SNPs ( $n=7$ or $n=6$ ) both Milano et al. (2014) and Westgaard et al. (2017) showed differentiation between the Bay of Biscay and the North Sea and/or Norwegian Sea samples and argued that the differences obtained using neutral and outlier loci are due to adaptation to local conditions. Although it is not unusual to find adaptive divergences in fish even when neutral markers suggest panmixia at local level (HemmerHansen et al., 2007; Freamo et al., 2011), this does not seem to be the case for European hake. The analysis of a consensus panel of 116 outlier SNPs potentially under selective divergence confirmed the genetic structure observed with the total dataset with a 
295 stronger signal and failed in finding additional substructure, as observed before (Moore et al., 2014), suggesting that the genetic divergence observed in the European hake is not only due to selection. This contradicts the views of Milano et al. (2014) and Westgaard, et al. (2017), and further highlights the importance of using genome-wide based markers in order to reliable detect genetic differentiation and local adaptation.

European hake within the Bay of Biscay constitutes a seasonally stable homogeneous population

The lack of differentiation observed within the northwestern Iberian Peninsula and the eastern Bay of Biscay, with very low and not significant FST, suggests that all the specimens from the area are representative of a unique genetic population, partially solving the dubious genetic homogeneity present within the Bay of Biscay (Castillo et al., 2005; Pita et al., 2014; Pita et al., 2016). Additionally, in our study we have tested the seasonal stability of the European hake connectivity within the southern stock (northwestern Iberian Peninsula). Our analyses, based either on neutral or outlier loci do not show differentiation among samples collected in summer and winter within the northwestern Iberian Peninsula, supporting previous views (Lundy et al., 2000; Pita et al., 2016) and most likely explained by the fact that hake can spawn several times within the reproductive season (Murua et al., 2006; Murua, 2010). Yet, further studies with bigger and seasonal representative datasets and including only spawning individuals are necessary to better investigate any potential spatio-temporal sub-structuring within the

\section{Management implications}

In the northeast Atlantic, assessment and management of the European hake is done independently for two stocks, the southern and the northern, separated by the Capbreton Canyon. The biomass of both stocks was in historical minimum and below precautionary biological reference points in the last years of the previous century (ICES, 2018). At the beginning of the new century the stocks started recovering and now the biomass of both are above precautionary levels. In the case of the northern stock the recovery has been extraordinary and the current biomass level doubles the historical 
maximum estimated by the stock assessment model at the beginning of the 1980s. Furthermore, the fishing mortality is well below the maximum sustainable yield target. However, the recovery of the southern stock has not been sufficiently strong and although the biomass is above the reference levels the fishing mortality is still too high. This study suggest that the delimitation of the assessment and management areas should be revised. In terms of the assessment, the southern stock and the southern part of the northern stock should be assessed jointly, and a separate stock should be considered in the northern part of the species distribution which includes the Norwegian Sea and possibly the North Sea, although this has yet to be confirmed with additional analyses. Since 2006 the biomass of the northern stock has increased tenfold (ICES, 2018), resulting in an increased abundance of the stock in the North Sea during spring and summer (Baudron and Fernandes, 2015). Additionally, recent explicit stock assessment models (Vigier et al., 2018) predict significant movement between the North Sea and the Celtic Sea and the Bay of Biscay suggesting that, under the hypothesis of a separate population in the northern part of the distribution, the North Sea could be a mixing area of both populations.

In sum, our results support the need for defining new assessment and management units for European hake. Yet, despite covering a wide range of the species distribution, our study does not provide information on where the new stock boundary should be located; therefore, future studies including samples from additional locations between the southern Bay of Biscay and the Norwegian Sea are necessary. Importantly, genetic analyses should also be complemented with additional evidence based on alternative techniques (morphometrics, vital rates, etc...) that would help providing biologically meaningful information for adequately defined stock boundaries.

\section{Authors Contribution}

PA, FSR and NRE designed the study. AL and NRE analysed the data. AL, NRE and DG interpreted the data and wrote the first draft of the paper. All authors performed critical reading of the first draft and contributed to the revisions.

\section{Supplementary data}


Supplementary figures and tables are available at $\mathrm{X}$

\section{Acknowledgements}

362

363

This work has been supported by the Spanish Ministry of Economy and

Competitiveness (grant CTM2015-66676), and by the Department of Agriculture and Fisheries of the Basque and Government (grant GENPES). We wish to thank Arved Staby (Institute of Marine Research, Bergen), Sonia Rábade, Alex Alonso, Mariña Fabeiro and Laura Casas (IIM-CSIC), Ibon Cancio (EHU/UPV) and Maria Korta (AZTI) for providing samples, and Naroa Aldanondo, Iñaki Mendibil and Elisabete Bilbao (AZTI) for technical support. This manuscript is contribution number $X$ [to be added upon acceptance] from the Marine Research Division of AZTI.

\section{References}

Ahrens, C. W., Rymer, P. D., Stow, A., Bragg, J., Dillon, S., Umbers, K. D. L., and Dudaniec, R. Y. 2018. The search for loci under selection: trends, biases and progress. Molecular ecology, 27: 1342-1356.

Altschul, S. F., Gish, W., Miller, W., Myers, E. W., and Lipman, D. J. 1990. Basic local alignment search tool. J Mol Biol, 215: 403-410.

Andrews, S. 2010. FastQC: a quality control tool for high throughput sequence data. http://www.bioinformatics.babraham.ac.uk/projects/fastqc.

Baudron, A. R., and Fernandes, P. G. 2015. Adverse consequences of stock recovery: European hake, a new "choke" species under a discard ban? Fish and Fisheries, 16: 563-575.

Bernatchez, L., Wellenreuther, M., Araneda, C., Ashton, D. T., Barth, J. M. I., Beacham, T. D., Maes, G. E., et al. 2017. Harnessing the Power of Genomics to Secure the Future of Seafood. Trends in Ecology \& Evolution, 32: 665-680.

Bonfil, R. 2005. Management Techniques for Elasmobranch Fisheries. In FAO Fisheries Technical Paper 474, pp. 6-14. Ed. by R. B. John Musick. FAO.

Casey, J., and Pereiro, J. 1995. European Hake (M. merluccius) in the Northeast Atlantic. In Hake: Biology, Fisheries and markets, pp. 125-147. Chapman \& Hall, London.

Castillo, A. G. F., Alvarez, P., and Garcia-Vazquez, E. 2005. Population structure of Merluccius merluccius along the Iberian Peninsula coast. ICES Journal of Marine Science, 62: 16991704.

Catchen, J., Hohenlohe, P. A., Bassham, S., Amores, A., and Cresko, W. A. 2013. Stacks: an analysis tool set for population genomics. Molecular ecology, 22: 3124-3140.

de Pontual, H., Jolivet, A., Garren, F., and Bertignac, M. 2013. New insights on European hake biology and population dynamics from a sustained tagging effort in the Bay of Biscay. ICES Journal of Marine Science, 70: 1416-1428.

Díaz-Arce, N., and Rodríguez-Ezpeleta, N. 2019. Selecting RAD-Seq Data Analysis Parameters for Population Genetics: The More the Better? Frontiers in Genetics, 10. 
401

402

403

404

405

406

407

408

409

410

411

412

413

414

415

416

417

418

419

420

421

422

423

424

425

426

427

428

429

430

431

432

433

434

435

436

437

438

439

440

441

442

443

444

445

446

447

448

449

450

451

Dominguez-Petit, R. 2017. Study of Reproductive Potential of Merluccius merluccius in the Galician Shelf., p. 253 University of Vigo.

Earl, D. A., and vonHoldt, B. M. 2012. STRUCTURE HARVESTER: a website and program for visualizing STRUCTURE output and implementing the Evanno method. Conservation Genetics Resources, 4: 359-361.

Evanno, G., Regnaut, S., and Goudet, J. 2005. Detecting the number of clusters of individuals using the software structure: a simulation study. Molecular ecology, 14: 2611-2620.

Excoffier, L., and Lischer, H. E. L. 2010. Arlequin suite ver 3.5: a new series of programs to perform population genetics analyses under Linux and Windows. Mol Ecol Resour, 10: 564-567.

Foll, M., and Gaggiotti, O. 2008. A genome-scan method to identify selected loci appropriate for both dominant and codominant markers: a Bayesian perspective. Genetics, 180: 977993.

Freamo, H., O'Reilly, P., Berg, P. R., Lien, S., and Boulding, E. G. 2011. Outlier SNPs show more genetic structure between two Bay of Fundy metapopulations of Atlantic salmon than do neutral SNPs. Mol Ecol Resour, 11: 254-267.

Hauser, L., and Carvalho, G. R. 2008. Paradigm shifts in marine fisheries genetics: ugly hypotheses slain by beautiful facts. Fish and Fisheries, 9: 333-362.

Hemmer-Hansen, J., Nielsen, E. E., Frydenberg, J., and Loeschcke, V. 2007. Adaptive divergence in a high gene flow environment: Hsc70 variation in the European flounder (Platichthys flesus L.). Heredity, 99: 592.

ICES 2011. Report of the Working Group on the Assessment of Southern Shelf stocks of Hake, Monk and Megrim (WGHMM). ICES CM 2011/ACOM:11.625 pp.

ICES 2018. Report of the Working Group for the Bay of Biscay and the Iberian Waters Ecoregion (WGBIE). ICES CM 2018/ACOM:12. 585 pp.

Jakobsson, M., and Rosenberg, N. A. 2007. CLUMPP: a cluster matching and permutation program for dealing with label switching and multimodality in analysis of population structure. Bioinformatics, 23: 1801-1806.

Jombart, T., and Ahmed, I. 2011. adegenet 1.3-1: new tools for the analysis of genome-wide SNP data. Bioinformatics, 27: 3070-3071.

Jombart, T., Devillard, S., and Balloux, F. 2010. Discriminant analysis of principal components: a new method for the analysis of genetically structured populations. BMC Genet, 11.

Korta, M., García, D., Santurtún, M., Goikoetxea, N., Andonegi, E., Murua, H. M., Álvarez, P., et al. 2015. European hake (Merluccius merluccius) in the Northeast Atlantic Ocean. In Hakes.

Lundy, C. J., Moran, P., Rico, C., Milner, R. S., and Hewitt, G. M. 1999. Macrogeographical population differentiation in oceanic environments: a case study of European hake (Merluccius merluccius), a commercially important fish. Molecular ecology, 8: 18891898.

Lundy, C. J., Rico, C., and Hewitt, G. M. 2000. Temporal and spatial genetic variation in spawning grounds of European hake (Merluccius merluccius) in the Bay of Biscay. Molecular ecology, 9: 2067-2079.

Luu, K., Bazin, E., and Blum, M. G. B. 2016. pcadapt: An R package to perform genome scans for selection based on principal component analysis. Mol Ecol Resour, 33: 67-77.

Milano, I., Babbucci, M., Cariani, A., Atanassova, M., Bekkevold, D., Carvalho, G. R., Espiñeira, M., et al. 2014. Outlier SNP markers reveal fine-scale genetic structuring across European hake populations (Merluccius merluccius). Molecular ecology, 23: 118-135.

Moore, J.-S., Bourret, V., Dionne, M., Bradbury, I., O'Reilly, P., Kent, M., Chaput, G., et al. 2014. Conservation genomics of anadromous Atlantic salmon across its North American range: outlier loci identify the same patterns of population structure as neutral loci. Molecular ecology, 23: 5680-5697. 
Murua, H. 2010. Chapter two - The Biology and Fisheries of European Hake, Merluccius merluccius, in the North-East Atlantic. In Advances in Marine Biology, pp. 97-154. Ed. by M. Lesser. Academic Press.

Murua, H., Lucio, P., Santurtún, M., and Motos, L. 2006. Seasonal variation in egg production and batch fecundity of European hake Merluccius merluccius (L.) in the Bay of Biscay. Journal of Fish Biology, 69: 1304-1316.

Narum, S. R., and Hess, J. E. 2011. Comparison of FST outlier tests for SNP loci under selection. Mol Ecol Resour, 11: 184-194.

Nielsen, E. E., Hemmer-Hansen, J., Larsen, P. F., and Bekkevold, D. 2009. Population genomics of marine fishes: identifying adaptive variation in space and time. Molecular ecology, 18: 3128-3150.

Nielsen, E. E., and Kenchington, E. 2001. A new approach to prioritizing marine fish and shellfish populations for conservation. Fish and Fisheries, 2: 328-343.

Pita, A., Leal, A., Santafé-Muñoz, A., Piñeiro, C., and Presa, P. 2016. Genetic inference of demographic connectivity in the Atlantic European hake metapopulation (Merluccius merluccius) over a spatio-temporal framework. Fisheries Research, 179: 291-301.

Pita, A., Pérez, M., Balado, M., and Presa, P. 2014. Out of the Celtic cradle: The genetic signature of European hake connectivity in South-western Europe. Journal of Sea Research, 93: 90-100.

Pita, A., Pérez, M., Cerviño, S., and Presa, P. 2011. What can gene flow and recruitment dynamics tell us about connectivity between European hake stocks in the Eastern North Atlantic? Continental Shelf Research, 31: 376-387.

Pritchard, J. K., Stephens, M., and Donnelly, P. 2000. Inference of population structure using multilocus genotype data. Genetics, 155: 945-959.

Purcell, S., Neale, B., Todd-Brown, K., Thomas, L., Ferreira, M. A. R., Bender, D., Maller, J., et al. 2007. PLINK: A Tool Set for Whole-Genome Association and Population-Based Linkage Analyses. The American Journal of Human Genetics, 81: 559-575.

$R$ Core Team 2018. R: A language and environment for statistical computing. $R$ Foundation for Statistical Computing. Vienna, Austria.

Reiss, H., Hoarau, G., Dickey-Collas, M., and Wolff, W. J. 2009. Genetic population structure of marine fish: mismatch between biological and fisheries management units. Fish and Fisheries, 10: 361-395.

Rodriguez-Ezpeleta, N., Álvarez, P., and Irigoien, X. 2017. Genetic Diversity and Connectivity in Maurolicus muelleri in the Bay of Biscay Inferred from Thousands of SNP Markers. Frontiers in Genetics, 8: 195.

Rodríguez-Ezpeleta, N., Bradbury, I. R., Mendibil, I., Álvarez, P., Cotano, U., and Irigoien, X. 2016. Population structure of Atlantic mackerel inferred from RAD-seq-derived SNP markers: effects of sequence clustering parameters and hierarchical SNP selection. Mol Ecol Resour, 16: 991-1001.

Roldán, M. I., García-Marín, J. L., Utter, F. M., and Pla, C. 1998. Population genetic structure of European hake, Merluccius merluccius. Heredity, 81: 327.

Rosenberg, N. A. 2004. DISTRUCT: a program for the graphical display of population structure. Molecular Ecology Notes, 4: 137-138.

Swan, S. C., Geffen, A. J., Morales-Nin, B., Gordon, J. D. M., Shimmield, T., Sawyer, T., and Massutí, E. 2006. Otolith chemistry: an aid to stock separation of Helicolenus dactylopterus (bluemouth) and Merluccius merluccius (European hake) in the Northeast Atlantic and Mediterranean. ICES Journal of Marine Science, 63: 504-513.

Tanner, S., Vasconcelos, R., Cabral, H., and Thorrold, S. 2012. Testing an otolith geochemistry approach to determine population structure and movements of European hake in the northeast Atlantic Ocean and Mediterranean Sea. 125-126: 198-205.

Vigier, A., Mahévas, S., and Bertignac, M. 2018. Towards a spatial integrated stock assessment model for European hake northern stock. 199: 158-170. 
504 Westgaard, J.-I., Staby, A., Aanestad Godiksen, J., Geffen, A. J., Svensson, A., Charrier, G., Svedäng, H., et al. 2017. Large and fine scale population structure in European hake (Merluccius merluccius) in the Northeast Atlantic. ICES Journal of Marine Science, 74: 1300-1310.

508

509

510 


\section{Tables}

512

513 Table 1: Observed and expected heterozygosities per group of samples when using all

514 or only outlier SNPs. MED: Mediterranean Sea; EBOB: Eastern Bay of Biscay; NWIPs:

515 Northwestern Iberian Peninsula (summer); NWIPw: Northwestern Iberian Peninsula

516 (winter); NOR: Norwegian Sea

\begin{tabular}{cccccc} 
POP & $\mathbf{n}$ & \multicolumn{2}{c}{$\mathbf{1 4 1 2 0}$ total SNPs } & \multicolumn{2}{c}{$\mathbf{1 1 6}$ outlier SNPs } \\
\hline & & Ho & He & Ho & He \\
\hline MED & 14 & 0.25732 & 0.26521 & 0.29418 & 0.30206 \\
EBOB & 18 & 0.24744 & 0.24918 & 0.27476 & 0.27110 \\
NWIPs & 30 & 0.23193 & 0.24219 & 0.27043 & 0.27541 \\
NWIPw & 30 & 0.2348 & 0.24144 & 0.25000 & 0.24945 \\
NOR & 18 & 0.25252 & 0.25221 & 0.31828 & 0.31676
\end{tabular}

517

518

519 Table 2: Pairwise FST value matrix when using all or only outlier SNPs (below and above 520 diagonal respectively). Values in bold are significant after Bonferroni correction for 521 multiple testing.

522

$\begin{array}{llllll} & \text { MED } & \text { EBOB } & \text { NWIPs } & \text { NWIPw } & \text { NOR } \\ \text { MED } & / & \mathbf{0 . 4 6 4} & \mathbf{0 . 4 4 3} & \mathbf{0 . 4 8 0} & \mathbf{0 . 4 7 0} \\ \text { EBOB } & \mathbf{0 . 0 5 2} & / & 0.008 & 0.005 & \mathbf{0 . 4 9 6} \\ \text { NWIPs } & \mathbf{0 . 0 4 8} & 0 & / & 0.005 & \mathbf{0 . 4 5 3} \\ \text { NWIPw } & \mathbf{0 . 0 4 9} & 0 & 0 & / & \mathbf{0 . 4 9 8} \\ \text { NOR } & \mathbf{0 . 0 5 8} & \mathbf{0 . 0 2 5} & \mathbf{0 . 0 2 3} & \mathbf{0 . 0 2 5} & /\end{array}$


Figures

527

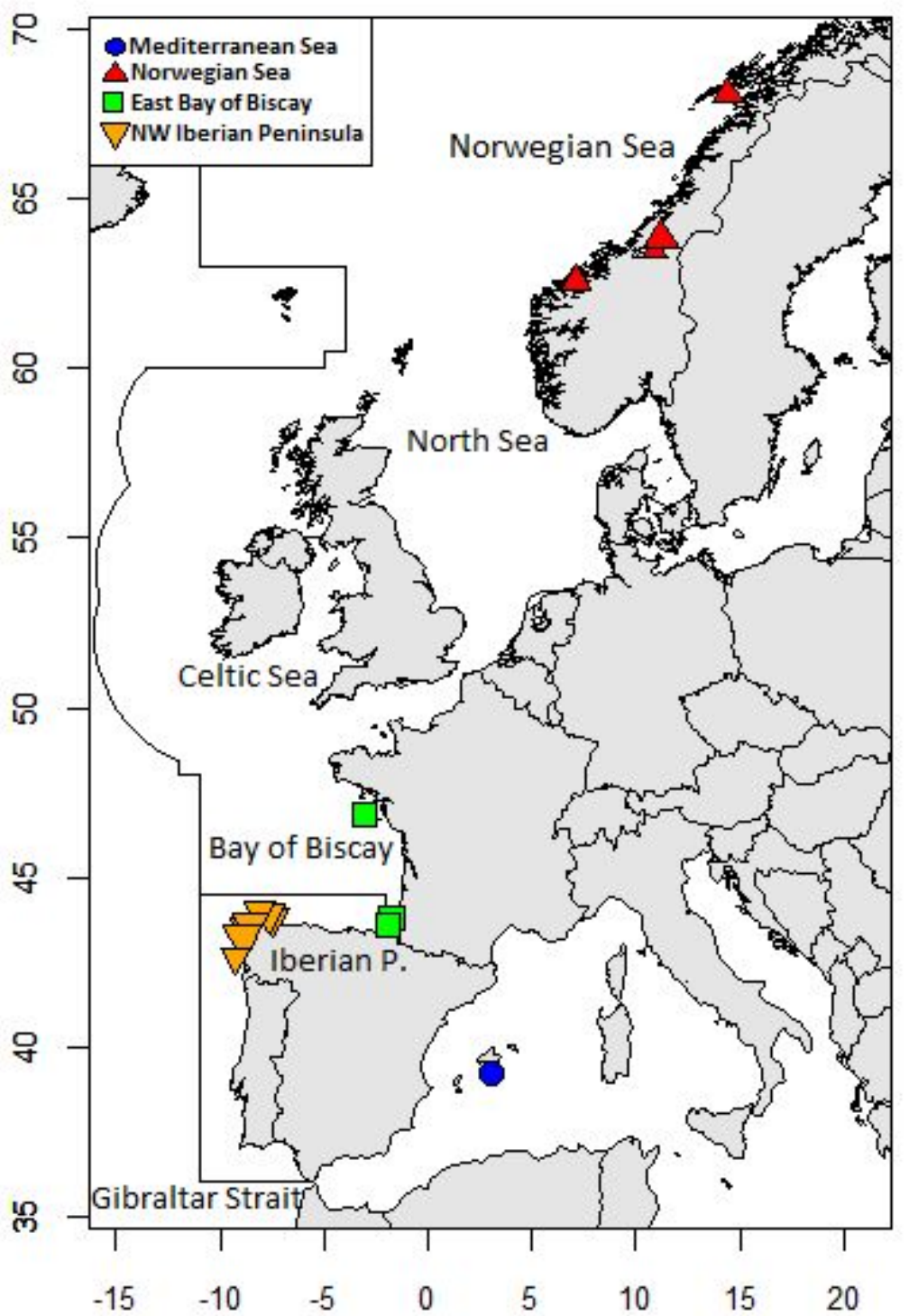

530 Figure 1: Sampling sites of European hake and ICES delimitation for the Northern (top)

531 and Southern (bottom) stock management units. The border between Northern and

532 Southern stocks approximate the Capbreton Canyon. 

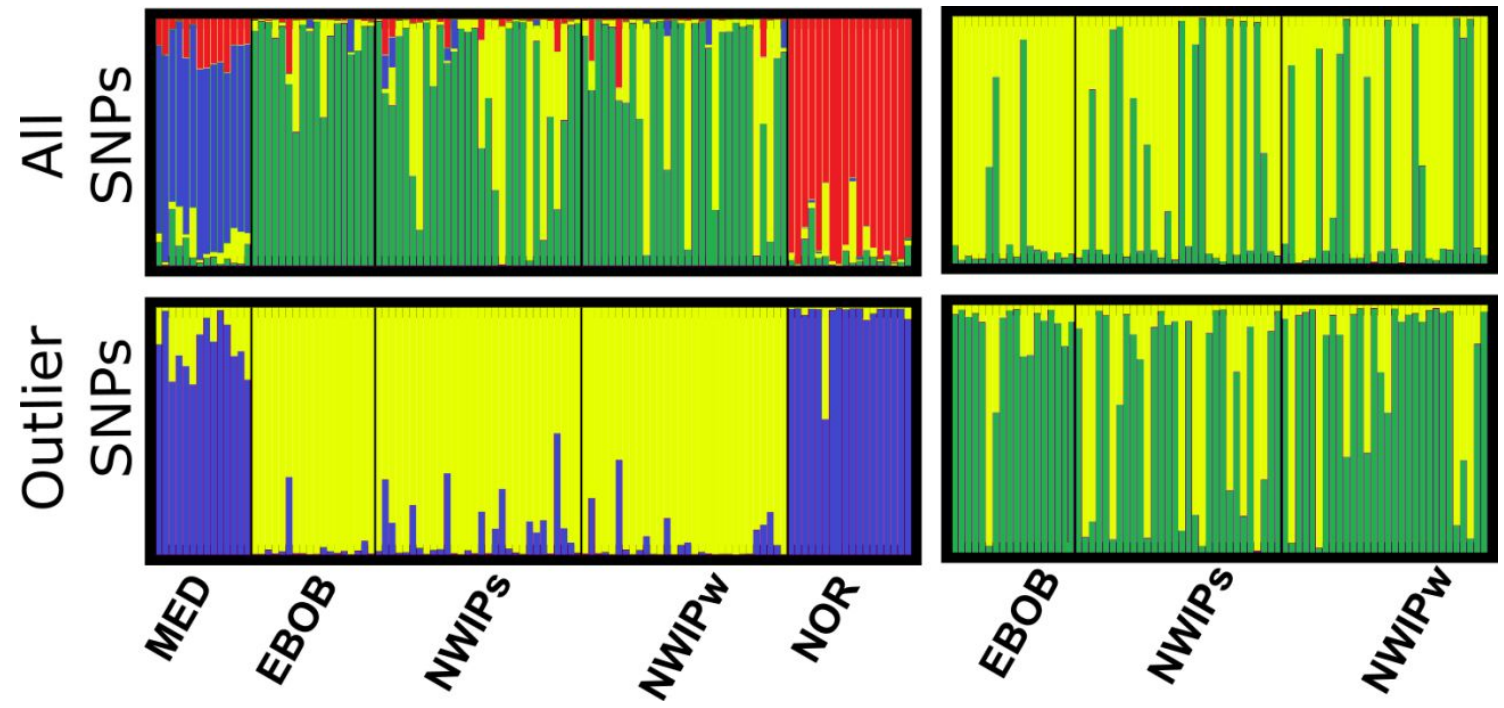

535

Figure 2: Graphical representation of the Bayesian clustering approach implemented in

537 STRUCTURE when using all (top) or only outlier SNPs (bottom) and all (left) or only the

538 Eastern Bay of Biscay and Northwestern Iberian Peninsula samples (right) for the best K 539 value according to the Evanno method, which is $\mathrm{K}=2$ for all dataset except for the all 540 SNPs all samples dataset, for which it is $\mathrm{K}=4$. Refer to Table 1 for location codes. 


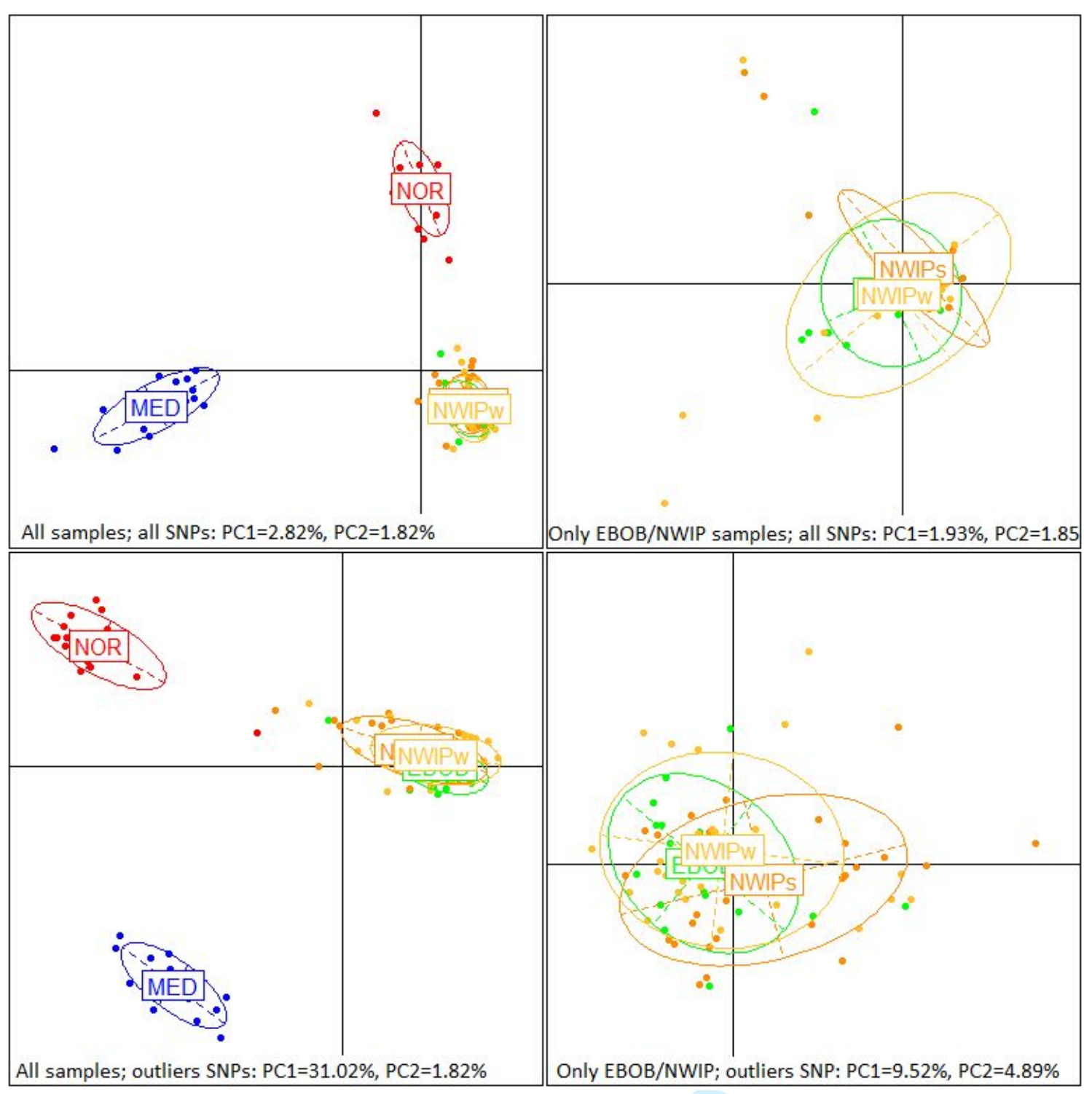

Figure 3: Principal Component Analysis (PCA) when using all (top) or only outlier SNPs

545 (bottom) and all (left) or only the Eastern Bay of Biscay and Northwestern Iberian 546 Peninsula samples (right). The variance explained by each axis of the PCA reflects the 547 amount of variation observed when using the total or the outlier SNPs dataset. 
1 Genome-wide SNP based population structure in European hake reveals the need for

2 harmonizing biological and management units

3

4 Agostino Leone ${ }^{1}$, Paula Álvarez ${ }^{1}$, Dorleta García ${ }^{1}$, Fran Saborido-Rey², Naiara Rodriguez-

$5 \quad$ Ezpeleta ${ }^{1, *}$

6

$7 \quad{ }^{1}$ AZTI, Marine Research Division, Txatxarramendi ugartea z/g, 48395 Sukarrieta, Bizkaia, 8 Spain

92 IIM-CSIC, Institute of Marine Research, Eduardo Cabello 6, 36208 Vigo, Pontevedra, 10 Spain

11 * Corresponding author: tel: +34 667174 514; email: nrodriguez@azti.es

12

13

14 


\section{Abstract (<200 words)}

16 Despite its economic importance, the population structure of the European hake,

17 Merluccius merluccius, is unresolved, and the species is assessed based on two stocks 18 (northern and southern) separated by the Capbreton Canyon. In order to shed light into 19 the European hake population structure, here we have discoveredwe used Restriction 20 site Associated DNA sequencing (RAD-seq) to discover and genotypedgenotype thousands of genome-wide single nucleotide polymorphisms in more than a hundred samples. Our population genetic inferences confirm differentiation of Mediterranean and northeast Atlantic locations and reveal management relevant information within the latter. First, the hake in the Norwegian Sea is genetically different from that of the rest of the locations under study and, second, samples from the eastern Bay of Biscay and the northwestern Iberian Peninsula are not genetically different. These results imply that samples from the northern stock belong to different genetic populations, and that samples belonging to locations included in the northern and southern stocks are part of a single genetically homogeneous population. Although the definition of the boundary between the northern and southern stocks and the potential need for additional stocks still requires further analyses, the mismatch between biological and management units should already be considered in further assessments of European hake.

Keywords: RAD-seq; SNPs; stock delimitation; genetic connectivity; European Hake; fisheries management 


\section{Introduction}

Determining spatiotemporal genetic variation is important for sustainable fisheries management (Hauser and Carvalho, 2008). Yet, intrinsic characteristics of marine fish such as large population sizes, high dispersal capacity and large numbers of effspringhigh fecundity often translate into low genetic variationdifferentiation even at interoceanic distances (Nielsen and Kenchington, 2001; Nielsen et al., 2009). This often results in a mismatch between biological and management units (Reiss et al., 2009), which can tedlead to reduced productivity, local reduction of populations and in extreme cases, to local population collapse (Bonfil, 2005). An example of potential mismatch between biological and management units is the European hake (Merluccius merluccius) (Reiss et al., 2009), an important commercial fish that inhabits the Northeast Atlantic Ocean and adjacent seas (Korta et al., 2015; ICES, 2018). Within the Northeast Atlantic Ocean, the European hake is managed by the International Council for the Exploration of the Sea (ICES) assuming two stocks separated by the Capbreton Canyon, the northern stock goingextending northward to Norway (ICES Division 3a, Sub-areas 2, 4, 6 and 7, and Divisions 8a,b,d) and the southern stock, southward to Gibraltar Strait (ICES Divisions 8c and 9a) (ICES, 2011; ICES, 2018). Yet, this separation is not based on clear biological evidences other than the assumption of the barrier effect of the Capbreton Canyon (Casey and Pereiro, 1995). Additionally, in locations from the northern stock (e.g. Bay of Biscay), the main spawning season ranges from January to March, whereas in locations from the southern stock (Galicia and Portugal), spawning occurs all year round with the presence of several other peaks in summer and autumn (Korta et al., 2015; Dominguez-Petit, 2017).

There is still no consensus on the population structure of the European hake (Roldán et al., 1998; Castillo et al., 2005; Pita et al., 2014). Studies based on otolith chemistry, which reflects where fish has been born and grown, have detected differences between samples from southern (represented by northern Portugal) and northern (represented by the Norwegian Sea and West of Scotland) stocks (Swan et al., 2006), whereas others (Tanner et al., 2012) found no significant differences between samples from the northern (represented by the Celtic Sea and the Armorican Shelf) and the southern stock 
73 (represented by samples from the Portugal and Galician Shelf). Early studies based on microsatellite genetic markers resulted in conflicting results. For example Lundy et al. (1999) found differentiation within samples from-the northern (e.g. Celtic Sea and Norwegian Sea) and southern (e.g. Cantabrian Sea and southern Portugal) stocks but no differentiation between samples belonging to two differentthe two stocks (e.g Celtic Sea and Bay of Biscay).-On the other hand, Castillo et al. (2005) confirmed nothe lack of differentiation between samples from the Bay of Biscay (ICES divisions 8c vs. 8a,b,d) belonging to the two stocks but found no differentiation between the Cantabrian Sea and Portuguese coast samples (ICES divisions 8 and 9). More recent studies using microsatellites have confirmed the lack of differentiation between Bay of Biscay samples belonging to northern and southern stocks and suggested a possible differentiation of North Sea samples (Pita et al., 2011; Pita et al., 2014).

Despite the advent of High Throughput Sequencing technologies and their demonstrated potential to study population structure in marine fish (Bernatchez et al., 2017), so far only one study has applied this technique to study population connectivity in the European hake (Milano et al., 2014), and is only based on 381 single nucleotide polymorphisms (SNPs), a very low number compared to the tens of thousands used in other studies aimed at resolving population structure of marine fish (Rodríguez-Ezpeleta et al., 2016; Rodriguez-Ezpeleta et al., 2017). In their work, Milano et al.(2014) did not find differentiation between northern and southern stocks when using neutral markers but found differentiation within the southern (between Galicia and North Portugal) and within the northern (between North Sea and the other locations) stocks when using 7 outlier loci. This result was further confirmed by another study based on a subset of this dataset (Westgaard et al., 2017); yet, neutral markers did not show the differentiation observed with outlier loci, even when using a bigger sample size, meaning that additional and more powerful analyses are needed to better understandresolve the European hake population structure.

Here, we have discovered and genotyped genome-wide SNP markers in European hake to (i) define the population structure of this commercially important species along the Mediterranean-Norwegian gradient, (ii) investigate the possibility of seasonal genetic 
105

106

107

changes within southern stock samples, and (iii) test if the current assessment and management units and population structure of European hake coincide. In order to reach these goals, we generated Restriction-site-Associated DNA sequencing (RAD-seq) data from 111 European hake individuals that span four geographic areas where this species inhabits: the Norwegian Sea, the eastern Bay of Biscay, the northwestern Iberian Peninsula (including samples from both spawning seasons) and the Mediterranean Sea (Balearic Sea), enabling the opportunity to explore population genetic structure and scan for selective divergences in this species. Our study reveals a mismatch between biological populations and management units in the European hake, which should be considered in the assessment of this commercially important species.

\section{Materials and methods}

Sampling, DNA extraction and RAD-seq library preparation

European hake samples from the Mediterranean Sea, the northwestern Iberian Peninsula (southern stock), the eastern Bay of Biscay (northern stock) and the Norwegian Sea (northern stock) were obtained from scientific surveys and commercial fisheries (Figure 1; Table S1). Samples include fish in spawning and pre-spawning condition, assumed to be at or close to where they will spawn, and juveniles of age 0 (less than $20 \mathrm{~cm}$ ), assumed to be close to where they were born (de Pontual et al., 2013). From each specimen, a $\sim 1 \mathrm{~cm}^{3}$ muscle sample was excised and stored in $96 \%$ molecular grade ethanol at $-20^{\circ} \mathrm{C}$ prior to DNA extraction. Genomic DNA was extracted from about $20 \mathrm{mg}$ of muscle tissue using the Wizard ${ }^{\circledR}$ Genomic DNA Purification kit (Promega, WI, USA) following manufacturer's instructions-for "Isolating Genomic DNA from Tissue Culture Cells and Animal Tissue".. Extracted DNA was suspended in Milli-Q water and concentration was determined with the Quant-iT dsDNA HS assay kit using a Qubit ${ }^{\circledR} 2.0$ Fluorometer (Life Technologies). DNA integrity was assessed by electrophoresis; migrating about $100 \mathrm{ng}$ of GelRed ${ }^{\mathrm{TM}}$-stained DNA on an agarose $1.0 \%$ get.. RAD-seq libraries were prepared following the methods of Etter et al. (2011). Between 300 and $400 \mathrm{ng}$ of genomic DNA per sample was digested using the Sbfl restriction enzyme and 
137 then ligated to modified Illumina P1 adapters containing 5bp uniquesample-specific 138 barcodes. Pools of 32 DNA samples were sheared using the Covaris ${ }^{\circledR}$ M220 Focused139 ultrasonicator $^{\mathrm{TM}}$ Instrument (Life Technologies) and size-selected to $300-500 \mathrm{pb}$ by 140 cutting DNA fragments migrated though an agarose gel. Following the ligation of the 141 Illumina P2 adaptors, each genomic library was amplified using 12 PCR cycles. Finally, 142 the pools were paired-end sequenced (100 bp) on an Illumina HiSeq2000.-Raw 143 sequences are available at NCBI SRA Bioproject \# X [to be added upon acceptance].

RAD-tag assembly and SNP calling

Generated RAD-tags were analyzed using Stacks version 2.1 (Catchen et al., 2013). Quality filtering and demultiplexing was performed using the Stacks module process_radtags, truncating all reads to 90 nucleotides after sequence quality verification in FastQC (Andrews, 2010) in order to avoid lower quality bases at the end of the read. The module clone filter was applied to reads whose forward and reverse pairs passed quality filtering to remove PCR duplicates, and only samples with at least 400,000 clone and quality-filtered reads remaining were kept. The module ustacks was then used to assemble orthologous tags (stacks) per individual, with a minimum coverage depth required to create a stack (parameter $-m$ ) of 5 , and a maximum nucleotide mismatches allowed between stacks (parameter $-M$ ) of 2. RAD loci were then assembled using the module cstacks with a maximum of 2 mismatches allowed between sample tags when generating the catalog (parameter $-n)$. Matches to the catalog for each sample were searched using sstacks. The module populations was used to export from the catalog the SNPs present in RAD loci found in at least $75 \%$ of the individuals. The software PLINK version 1.07 (Purcell et al., 2007) was used to further filter the data. The initial filtering steps were based on a maximum of $10 \%$ of missing values per locus, and a maximum of $25 \%$ of missing values per individual. Subsequently, SNPs with a minimum allele frequency (MAF) smaller than 0.05 and which failed the Hardy Weinberg equilibrium (HWE) test at $p<0.05$ in at least two areas of study were excluded from downstream analyses. Only the first filtered SNP of each RAD-tag was kept. Additionally, an alternative dataset with $M=4$ and $n=6$ (keeping the rest of the parameters unchanged) and another with MAF threshold of 0.1 (keeping the rest of the parameters 
169 unchanged) were also explored for consistency as suggested (Díaz-Arce and Rodríguez170 Ezpeleta, 2019)(Díaz-Arce and Rodríguez-Ezpeleta, 2019). The genotype files are 171 available at $\mathrm{X}$ [to be added upon acceptance].

Identification of outlier loci

175 Outlier loci, potentially under selection, were identified using the independent approaches used by Bayescan version 2.0 (Foll and Gaggiotti, 2008) and Arlequin version 3.5.2.2 (Excoffier and Lischer, 2010) using the whole dataset and only the Bay of Biscay (Western and Eastern) samples. In Bayescan, 20 pilot runs of 5,000 iterations each were run, with a burn-in of 50,000 iterations, 5,000 samples with a thinning interval of 10 and a prior odd increased to 100 in order to minimize potentially false positives in a dataset with $>10,000$ loci. Using these parameters, loci with an $\alpha$-value significantly $>0$ (indicative of diversifying selection) and q-values $<0.05$ were considered "outliers". In addition, in the hierarchical Fdist model implemented in Arlequin, loci with significantly higher FST values $(p<0.001)$ were considered "outliers". These stringent parameters were used to account for potential false positive outliers discovery (Narum and Hess, 2011; Ahrens et al., 2018). Outputs from Bayescan and Arlequin were intersected in order to create a consensus panel of shared loci potentially under selection-which were annotated by which were annotated by matching the SNP flanking regions against nonredundant database of Genbank (www.ncbi.nlm.nih.gov/genbank/) using BLAST (Altschul et al., 1990). In addition, a multivariate approach to outlier loci discovery was also applied using the package pcadapt (Luu et al., 2016) in R version 3.5.0 (R Core Team, 2018).

Genetic diversity and structure analyses

Analyses where performed on the whole SNP dataset, on the neutral SNP dataset and on the outlier SNP dataset. Expected and observed heterozygosity per group (He and Ho respectively), pairwise average FST among groups and distributions of FST and FIS values were computed with Arlequin version 3.5.2.2 (Excoffier and Lischer, 2010). Principal component analyses (PCA) and a three-cluster based discriminant analyses of principal 
201 components (DAPC) (Jombart et al., 2010) were performed without any a priori

202

203

204

205

206

207

208

209

210

211

212

213

214

215

216

217

218

219

220

221

222

223

224

225

226

227

228

229

230

231

232 assignment of individuals to populations using the package adegenet (Jombart and Ahmed, 2011) in R version 3.5.0 (R Core Team, 2018). The best number of PCs to retain for the DAPC analysis was inferred using the cross-validation test. The genetic ancestry of each individual was estimated using the admixture model as implemented in the Bayesian clustering approach in STRUCTURE version 2.3.4 (Pritchard et al., 2000) without any prior population assignment. Estimations were obtained from the 300,000 iterations that followed a burn-in period of 100,000 iterations. Each value of potential ancestral population ( $\mathrm{K}$ from 1 to 5 ) was examined with CLUMPP (Jakobsson and Rosenberg, 2007) to identify common modes, and results were plotted using DISTRUCT (Rosenberg, 2004). The value of $K$ that better fits the data was identified according to the Evanno method (Evanno et al., 2005) as implemented in StructureHarvester (Earl and vonHoldt, 2012). Additionally, ten subsets of 300 randomly selected SNPs were analyzed with $\mathrm{K}=3$ in order to investigate the effect of using a smaller dataset of genomewide representative SNPs.

\section{Results}

SNP datasets

Of the 111 analyzed samples, only one was removed for having too few reads. Considering the remaining samples, between 402599 and 3053042 quality-filtered RAD-tags per individual were obtained (average of 1365 352). Ninety percent of the reads were used to build the stacks, with a range per individual between $81 \%$ and $95 \%$, and the average effective per-sample coverage is $34.1 x$ (stdev $=12.8 x, \min =11.3 x$, $\max =72.9 x)$. The number of RAD-loci present in at least $75 \%$ of the individuals was 29 090, totaling 452702 SNPs. After filtering for missing data, minor allele frequency and Hardy-Weinberg equilibrium and keeping a single SNP per tag, the number of RAD-loci and SNPs remaining for analysis was 14120 (Figure S1). The amount of missing data in was less than $5 \%$ overall, and no significant patterns ( $p$ value $=\underline{\text { datasets with } 0.01) \text { and }}$ $\underline{1 \%}$ of missingness between groupsmissing data, albeit composed of individuals were found. Fromfewer SNPs produced equivalent results (not shown). Of the remaining 
233 SNPs, 147 ( $1 \%$ of the total) and 217 SNPs (1.5\% of the total) were considered outliers 234 according to the Bayesian approach implemented in Bayescan and the hierarchical Fdist 235 model implemented in Arlequin when using the whole dataset (Figure S2), and 116 of them were common to both approaches. No outlier loci were found when using only the northwestern Iberian Peninsula and the Eastern Bay of Biscay samples. Additionally, 347 SNPs (2.4\% of the total) were considered outliers according to the multivariate approach implemented in pcadapt. Of these loci, 108 were included in the 116 shared outlier datasets by Bayescan and Arlequin. Annotation of each of the outlier SNPs is available in Table S2.

Genetic diversity and population structure

Ranges of observed and expected heterozygosity per groups were similar, both when using the whole or the only outlier SNP dataset, indicating no deficits of heterozygous genotypes in all samples (Table 1). STRUCTURE analyses using the best $K$ values according to the Evanno method for the whole or the outlier only datasets (Table S3) resulted in three well differentiated clusters: i) the Mediterranean Sea samples, ii) the northwestern Iberian Peninsula and the eastern Bay of Biscay samples and iii) the Norwegian Sea samples (Figure 2), with no further structure observed when including only the eastern Bay of Biscay and the northwestern Iberian Peninsula samples. Analyses based on higher values of $\mathrm{K}$ resulted in no further differentiation (Figure S3) and analyses). Analyses based on ten subsets of 300 randomly selected SNPs datasets resulted in theprovided varying results (Figures S4): same differentiation pattern (5-of thefive subsets), in no differentiation within the Atlantic (4 of thefour subsets)-or in differentiation between the Mediterranean plus Norwegian Sea samples and the northwestern Iberian Peninsula plus the eastern Bay of Biscay samples (Figures S4one subset).The Analysis of Principal Components (PCA) on the whole dataset were congruent with the STRUCTURE analyses, revealing the same three well differentiated groups (Figure 3), even with alternative RAD-tag assembly parameter and MAF threshold values (Figure S5), and with the Discriminant Analysis of Principal Component (DAPC) when using three clusters (Figure S6). 
265 The locus-by-locus FST and FIS were distributed around zero (Figure S7) suggesting a

266

267

268

269

270

271

272

273

274

275

276

277

278

279

280

281

282

283

284

285

286

287

288

289

290

291

292

293

294

295

296

balanced amount of heterozygosity and homozygosity along the loci-, which is congruent with the low number of outliers detected. Pairwise FST values among the three differentiated areas were significant ranging from 0.023 to 0.058 , from 0.443 to 0.498 and from 0.014 to 0.042 (Table 2, S4 and S4S5) when using all, only the outlier SNPs and only the neutral SNPs respectively. Low and not significant differentiation was detected within samples from southern Europe, even when using only adult samples or only outlier SNPs suggesting that all samples from the Northern Spanish coast are part of a single population with no seasonal demographic changes.

\section{Discussion}

Genome-wide population structure of European hake does not support current stock delineation

Our genome-wide marker-based population structure inference of European hake supports differentiation between Mediterranean and Northeast Atlantic hake. Within the Northeast Atlantic, our study showed a clear differentiation between the Norwegian seasea and southern Europe ${ }_{2}$ but did not find differences between samples of the Bay of Biscay and northwestern Iberian Peninsula, belonging to the northern and southern stocks. These results confirm previous findings using microsatellites that found no differentiation between samples within the Bay of Biscay and Celtic sea, but found differentiation between these regions and the Norwegian Sea (Lundy et al., 1999; Pita et al., 2014). Interestingly, the only previous study based on SNP markers (Milano et al., 2014) failed to detect population structure within the Northeast Atlantic when using neutral markers, which could be due to a lack of evolutionarily informative signal in the few (299) markers used. Yet, when we base our inferences in 300 randomly selected SNPs, we still observe population structure, although not allbut only in half of the ten subsets-are able to distinguish the three groups (Figures S4).. This suggests that using thousands of genome-wide distributed SNPS rather than-a few selected hundreds SNPS as in previous studies (Milano et al., 2014) are requirednot enough for a reliable 
297 inference of hake population structure. Using a small subset of outlier SNPs ( $n=7$ or $n=6$ )

298

299

300

301

302

303

304

305

306

307

308

309

310

311

312

313

314

315

316

317

318

319

320

321

322

323

324

325

326

327 both Milano et al. (2014) and Westgaard et al. (2017) showed differentiation between the Bay of Biscay and the North Sea and/or Norwegian Sea samples and argued that the differences obtained using neutral and outlier loci are due to adaptation to local conditions. -Although it is not unusual to find adaptive divergences in fish even when neutral markers suggest panmixia at local level (Hemmer-Hansen et al., 2007; Freamo et al., 2011), this does not seem to be the case for European hake. The analysis of a consensus panel of 116 outlier SNPs potentially under selective divergence confirmed the genetic structure observed with the total dataset with a stronger signal and failed in finding additional substructure, as observed before (Moore et al., 2014), suggesting that the genetic divergence observed in the European hake is not due to the direct effect of fitness only (Holderegger et al., 2006).only due to selection. This contradicts the views of Milano et al. (2014) and Westgaard, et al. (2017), and further highlights the importance of using genome-wide based markers in order to reliable detect genetic differentiation and local adaptation.

\section{European hake within the Bay of Biscay constitutes a seasonally stable homogeneous} population

The lack of differentiation observed within the northwestern Iberian Peninsula and the eastern Bay of Biscay, with very low and not significant FST, supportssuggests that all the specimens from the area are representative of a unique genetic population, partially solving the dubious genetic homogeneity present within the Bay of Biscay (Castillo et al., 2005; Pita et al., 2014; Pita et al., 2016). Additionally, in our study we have tested the seasonal stability of the European hake connectivity within the southern stock (northwestern Iberian Peninsula). Our analyses, based either on neutral or outlier loci do not show differentiation among samples collected in summer and winter within the northwestern Iberian Peninsula, supporting previous views (Lundy et al., 2000; Pita et al., 2016) and most likely explained by the fact that hake can spawn several times within the reproductive season (Murua et al., 2006; Murua, 2010). Yet, further studies with bigger and seasonal representative datasets and including only spawning individuals are 
necessary to better investigate any potential spatio-temporal sub-structuring within the Bay of Biscay.

\section{Management implications}

In the northeast Atlantic, assessment and management of the European hake is done independently for two stocks, the southern and the northern, separated by the Capbreton Canyon. The biomass of both stocks was in historical minimum and below precautionary biological reference points in the last years of the previous century (ICES, 2018). At the beginning of the new century the stocks started recovering and now the biomass of both are above precautionary levels. In the case of the northern stock the recovery has been extraordinary and the current biomass level doubles the historical maximum estimated by the stock assessment model at the beginning of the 1980s. Furthermore, the fishing mortality is well below the maximum sustainable yield target. However, the recovery of the southern stock has not been sufficiently strong and although the biomass is above the reference levels the fishing mortality is still too high. This study suggest that the delimitation of the assessment and management areas should be revised. In terms of the assessment, the southern stock and the southern part of the northern stock should be assessed jointly, and a separate stock should be considered in the northern part of the species distribution which includes the Norwegian Sea and possibly the North Sea, although this has yet to be confirmed with additional analyses. Since 2006 the biomass of the northern stock has increased tenfold (ICES, 2018), resulting in an increased abundance of the stock in the North Sea during spring and summer (Baudron and Fernandes, 2015). Additionally, recent explicit stock assessment models (Vigier et al., 2018) predict significant movement between the North Sea and the Celtic Sea and the Bay of Biscay suggesting that, under the hypothesis of a separate population in the northern part of the distribution, the North Sea could be a mixing area of both populations.

In sum, our results support the need for defining new assessment and management units for European hake. Yet, despite covering a wide range of the species distribution, our study does not provide information on where the new stock boundary should be located; therefore, future studies including samples from additional locations between the southern Bay of Biscay and the Norwegian Sea are necessary. Importantly, genetic 
360

361

362

363

364

365

366

367

368

369

370

371

372

373

374

375

376

377

378

379

380

381

382

383

384

385

386

387

388

389

390

391

392

393

394

395

analyses should also be complemented with additional evidence based on alternative techniques (morphometrics, vital rates, etc...) that would help providing biologically meaningful information for adequately defined stock boundaries.

\section{Authors Contribution}

PA, FSR and NRE designed the study. AL and NRE analysed the data. AL, NRE and DG interpreted the data and wrote the first draft of the paper. All authors performed critical reading of the first draft and contributed to the revisions.

\section{Supplementary data}

Supplementary figures and tables are available at $\mathrm{X}$

\section{Acknowledgements}

This work has been supported by the Spanish Ministry of Economy and Competitiveness (grant CTM2015-66676), and by the Department of Agriculture and Fisheries of the Basque and Government (grant GENPES). We wish to thank Arved Staby (Institute of Marine Research, Bergen), Sonia Rábade, Alex Alonso, Mariña Fabeiro and Laura Casas (IIM-CSIC), Ibon Cancio (EHU/UPV) and Maria Korta (AZTI) for providing samples, and Naroa Aldanondo, Iñaki Mendibil and Elisabete Bilbao (AZTI) for technical support. This manuscript is contribution number $X$ [to be added upon acceptance] from the Marine Research Division of AZTI.

\section{References}

Ahrens, C. W., Rymer, P. D., Stow, A., Bragg, J., Dillon, S., Umbers, K. D. L., and Dudaniec, R. Y. 2018. The search for loci under selection: trends, biases and progress. Molecular ecology, 27: 1342-1356.

Altschul, S. F., Gish, W., Miller, W., Myers, E. W., and Lipman, D. J. 1990. Basic local alignment search tool. J Mol Biol, 215: 403-410.

Andrews, S. 2010. FastQC: a quality control tool for high throughput sequence data. http://www.bioinformatics.babraham.ac.uk/projects/fastqc.

Baudron, A. R., and Fernandes, P. G. 2015. Adverse consequences of stock recovery: European hake, a new "choke" species under a discard ban? Fish and Fisheries, 16: 563-575. 
Bernatchez, L., Wellenreuther, M., Araneda, C., Ashton, D. T., Barth, J. M. I., Beacham, T. D., Maes, G. E., et al. 2017. Harnessing the Power of Genomics to Secure the Future of Seafood. Trends in Ecology \& Evolution, 32: 665-680.

Bonfil, R. 2005. Management Techniques for Elasmobranch Fisheries. In FAO Fisheries Technical Paper 474, pp. 6-14. Ed. by R. B. John Musick. FAO.

Casey, J., and Pereiro, J. 1995. European Hake (M. merluccius) in the Northeast Atlantic. In Hake: Biology, Fisheries and markets, pp. 125-147. Chapman \& Hall, London.

Castillo, A. G. F., Alvarez, P., and Garcia-Vazquez, E. 2005. Population structure of Merluccius merluccius along the Iberian Peninsula coast. ICES Journal of Marine Science, 62: 16991704.

Catchen, J., Hohenlohe, P. A., Bassham, S., Amores, A., and Cresko, W. A. 2013. Stacks: an analysis tool set for population genomics. Molecular ecology, 22: 3124-3140.

de Pontual, H., Jolivet, A., Garren, F., and Bertignac, M. 2013. New insights on European hake biology and population dynamics from a sustained tagging effort in the Bay of Biscay. ICES Journal of Marine Science, 70: 1416-1428.

Díaz-Arce, N., and Rodríguez-Ezpeleta, N. 2019. Selecting RAD-Seq Data Analysis Parameters for Population Genetics: The More the Better? Frontiers in Genetics, 10.

Dominguez-Petit, R. 2017. Study of Reproductive Potential of Merluccius merluccius in the Galician Shelf., p. 253 University of Vigo.

Earl, D. A., and vonHoldt, B. M. 2012. STRUCTURE HARVESTER: a website and program for visualizing STRUCTURE output and implementing the Evanno method. Conservation Genetics Resources, 4: 359-361.

Evanno, G., Regnaut, S., and Goudet, J. 2005. Detecting the number of clusters of individuals using the software structure: a simulation study. Molecular ecology, 14: 2611-2620.

Excoffier, L., and Lischer, H. E. L. 2010. Arlequin suite ver 3.5: a new series of programs to perform population genetics analyses under Linux and Windows. Mol Ecol Resour, 10: 564-567.

Foll, M., and Gaggiotti, O. 2008. A genome-scan method to identify selected loci appropriate for both dominant and codominant markers: a Bayesian perspective. Genetics, 180: 977993.

Freamo, H., O'Reilly, P., Berg, P. R., Lien, S., and Boulding, E. G. 2011. Outlier SNPs show more genetic structure between two Bay of Fundy metapopulations of Atlantic salmon than do neutral SNPs. Mol Ecol Resour, 11: 254-267.

Hauser, L., and Carvalho, G. R. 2008. Paradigm shifts in marine fisheries genetics: ugly hypotheses slain by beautiful facts. Fish and Fisheries, 9: 333-362.

Hemmer-Hansen, J., Nielsen, E. E., Frydenberg, J., and Loeschcke, V. 2007. Adaptive divergence in a high gene flow environment: Hsc70 variation in the European flounder (Platichthys flesus L.). Heredity, 99: 592.

ICES 2011. Report of the Working Group on the Assessment of Southern Shelf stocks of Hake, Monk and Megrim (WGHMM). ICES CM 2011/ACOM:11.625 pp.

ICES 2018. Report of the Working Group for the Bay of Biscay and the Iberian Waters Ecoregion (WGBIE). ICES CM 2018/ACOM:12. 585 pp.

Jakobsson, M., and Rosenberg, N. A. 2007. CLUMPP: a cluster matching and permutation program for dealing with label switching and multimodality in analysis of population structure. Bioinformatics, 23: 1801-1806.

Jombart, T., and Ahmed, I. 2011. adegenet 1.3-1: new tools for the analysis of genome-wide SNP data. Bioinformatics, 27: 3070-3071.

Jombart, T., Devillard, S., and Balloux, F. 2010. Discriminant analysis of principal components: a new method for the analysis of genetically structured populations. BMC Genet, 11.

Korta, M., García, D., Santurtún, M., Goikoetxea, N., Andonegi, E., Murua, H. M., Álvarez, P., et al. 2015. European hake (Merluccius merluccius) in the Northeast Atlantic Ocean. In Hakes. 
Lundy, C. J., Moran, P., Rico, C., Milner, R. S., and Hewitt, G. M. 1999. Macrogeographical population differentiation in oceanic environments: a case study of European hake (Merluccius merluccius), a commercially important fish. Molecular ecology, 8: 18891898.

Lundy, C. J., Rico, C., and Hewitt, G. M. 2000. Temporal and spatial genetic variation in spawning grounds of European hake (Merluccius merluccius) in the Bay of Biscay. Molecular ecology, 9: 2067-2079.

Luu, K., Bazin, E., and Blum, M. G. B. 2016. pcadapt: An R package to perform genome scans for selection based on principal component analysis. Mol Ecol Resour, 33: 67-77.

Milano, I., Babbucci, M., Cariani, A., Atanassova, M., Bekkevold, D., Carvalho, G. R., Espiñeira, M., et al. 2014. Outlier SNP markers reveal fine-scale genetic structuring across European hake populations (Merluccius merluccius). Molecular ecology, 23: 118-135.

Moore, J.-S., Bourret, V., Dionne, M., Bradbury, I., O'Reilly, P., Kent, M., Chaput, G., et al. 2014. Conservation genomics of anadromous Atlantic salmon across its North American range: outlier loci identify the same patterns of population structure as neutral loci. Molecular ecology, 23: 5680-5697.

Murua, H. 2010. Chapter two - The Biology and Fisheries of European Hake, Merluccius merluccius, in the North-East Atlantic. In Advances in Marine Biology, pp. 97-154. Ed. by M. Lesser. Academic Press.

Murua, H., Lucio, P., Santurtún, M., and Motos, L. 2006. Seasonal variation in egg production and batch fecundity of European hake Merluccius merluccius (L.) in the Bay of Biscay. Journal of Fish Biology, 69: 1304-1316.

Narum, S. R., and Hess, J. E. 2011. Comparison of FST outlier tests for SNP loci under selection. Mol Ecol Resour, 11: 184-194.

Nielsen, E. E., Hemmer-Hansen, J., Larsen, P. F., and Bekkevold, D. 2009. Population genomics of marine fishes: identifying adaptive variation in space and time. Molecular ecology, 18 : 3128-3150.

Nielsen, E. E., and Kenchington, E. 2001. A new approach to prioritizing marine fish and shellfish populations for conservation. Fish and Fisheries, 2: 328-343.

Pita, A., Leal, A., Santafé-Muñoz, A., Piñeiro, C., and Presa, P. 2016. Genetic inference of demographic connectivity in the Atlantic European hake metapopulation (Merluccius merluccius) over a spatio-temporal framework. Fisheries Research, 179: 291-301.

Pita, A., Pérez, M., Balado, M., and Presa, P. 2014. Out of the Celtic cradle: The genetic signature of European hake connectivity in South-western Europe. Journal of Sea Research, 93: 90-100.

Pita, A., Pérez, M., Cerviño, S., and Presa, P. 2011. What can gene flow and recruitment dynamics tell us about connectivity between European hake stocks in the Eastern North Atlantic? Continental Shelf Research, 31: 376-387.

Pritchard, J. K., Stephens, M., and Donnelly, P. 2000. Inference of population structure using multilocus genotype data. Genetics, 155: 945-959.

Purcell, S., Neale, B., Todd-Brown, K., Thomas, L., Ferreira, M. A. R., Bender, D., Maller, J., et al. 2007. PLINK: A Tool Set for Whole-Genome Association and Population-Based Linkage Analyses. The American Journal of Human Genetics, 81: 559-575.

$R$ Core Team 2018. R: A language and environment for statistical computing. $R$ Foundation for Statistical Computing. Vienna, Austria.

Reiss, H., Hoarau, G., Dickey-Collas, M., and Wolff, W. J. 2009. Genetic population structure of marine fish: mismatch between biological and fisheries management units. Fish and Fisheries, 10: 361-395.

Rodriguez-Ezpeleta, N., Álvarez, P., and Irigoien, X. 2017. Genetic Diversity and Connectivity in Maurolicus muelleri in the Bay of Biscay Inferred from Thousands of SNP Markers. Frontiers in Genetics, 8: 195. 
Rodríguez-Ezpeleta, N., Bradbury, I. R., Mendibil, I., Álvarez, P., Cotano, U., and Irigoien, X. 2016. Population structure of Atlantic mackerel inferred from RAD-seq-derived SNP markers: effects of sequence clustering parameters and hierarchical SNP selection. Mol Ecol Resour, 16: 991-1001.

Roldán, M. I., García-Marín, J. L., Utter, F. M., and Pla, C. 1998. Population genetic structure of European hake, Merluccius merluccius. Heredity, 81: 327.

Rosenberg, N. A. 2004. DISTRUCT: a program for the graphical display of population structure. Molecular Ecology Notes, 4: 137-138.

Swan, S. C., Geffen, A. J., Morales-Nin, B., Gordon, J. D. M., Shimmield, T., Sawyer, T., and Massutí, E. 2006. Otolith chemistry: an aid to stock separation of Helicolenus dactylopterus (bluemouth) and Merluccius merluccius (European hake) in the Northeast Atlantic and Mediterranean. ICES Journal of Marine Science, 63: 504-513.

Tanner, S., Vasconcelos, R., Cabral, H., and Thorrold, S. 2012. Testing an otolith geochemistry approach to determine population structure and movements of European hake in the northeast Atlantic Ocean and Mediterranean Sea. 125-126: 198-205.

Vigier, A., Mahévas, S., and Bertignac, M. 2018. Towards a spatial integrated stock assessment model for European hake northern stock. 199: 158-170.

Westgaard, J.-I., Staby, A., Aanestad Godiksen, J., Geffen, A. J., Svensson, A., Charrier, G., Svedäng, H., et al. 2017. Large and fine scale population structure in European hake (Merluccius merluccius) in the Northeast Atlantic. ICES Journal of Marine Science, 74: 1300-1310. 


\section{Tables}

524

525 Table 1: Observed and expected heterozygosities per group of samples when using all

526 or only outlier SNPs. MED: Mediterranean Sea; EBOB: Eastern Bay of Biscay; NWIPs:

527 Northwestern Iberian Peninsula (summer); NWIPw: Northwestern Iberian Peninsula 528 (winter); NOR: Norwegian Sea

\begin{tabular}{cccccc} 
POP & $\mathbf{n}$ & \multicolumn{2}{c}{$\mathbf{1 4 1 2 0}$ total SNPs } & \multicolumn{2}{c}{$\mathbf{1 1 6}$ outlier SNPs } \\
\hline & & Ho & He & Ho & He \\
\hline MED & 14 & 0.25732 & 0.26521 & 0.29418 & 0.30206 \\
EBOB & 18 & 0.24744 & 0.24918 & 0.27476 & 0.27110 \\
NWIPs & 30 & 0.23193 & 0.24219 & 0.27043 & 0.27541 \\
NWIPw & 30 & 0.2348 & 0.24144 & 0.25000 & 0.24945 \\
NOR & 18 & 0.25252 & 0.25221 & 0.31828 & 0.31676
\end{tabular}

529

530

531 Table 2: Pairwise FST value matrix when using all or only outlier SNPs (below and above 532 diagonal respectively). Values in bold are significant after Bonferroni correction for 533 multiple testing.

534

$\begin{array}{llllll} & \text { MED } & \text { EBOB } & \text { NWIPs } & \text { NWIPw } & \text { NOR } \\ \text { MED } & / & \mathbf{0 . 4 6 4} & \mathbf{0 . 4 4 3} & \mathbf{0 . 4 8 0} & \mathbf{0 . 4 7 0} \\ \text { EBOB } & \mathbf{0 . 0 5 2} & / & 0.008 & 0.005 & \mathbf{0 . 4 9 6} \\ \text { NWIPs } & \mathbf{0 . 0 4 8} & 0 & / & 0.005 & \mathbf{0 . 4 5 3} \\ \text { NWIPw } & \mathbf{0 . 0 4 9} & 0 & 0 & / & \mathbf{0 . 4 9 8} \\ \text { NOR } & \mathbf{0 . 0 5 8} & \mathbf{0 . 0 2 5} & \mathbf{0 . 0 2 3} & \mathbf{0 . 0 2 5} & /\end{array}$


Figures

539

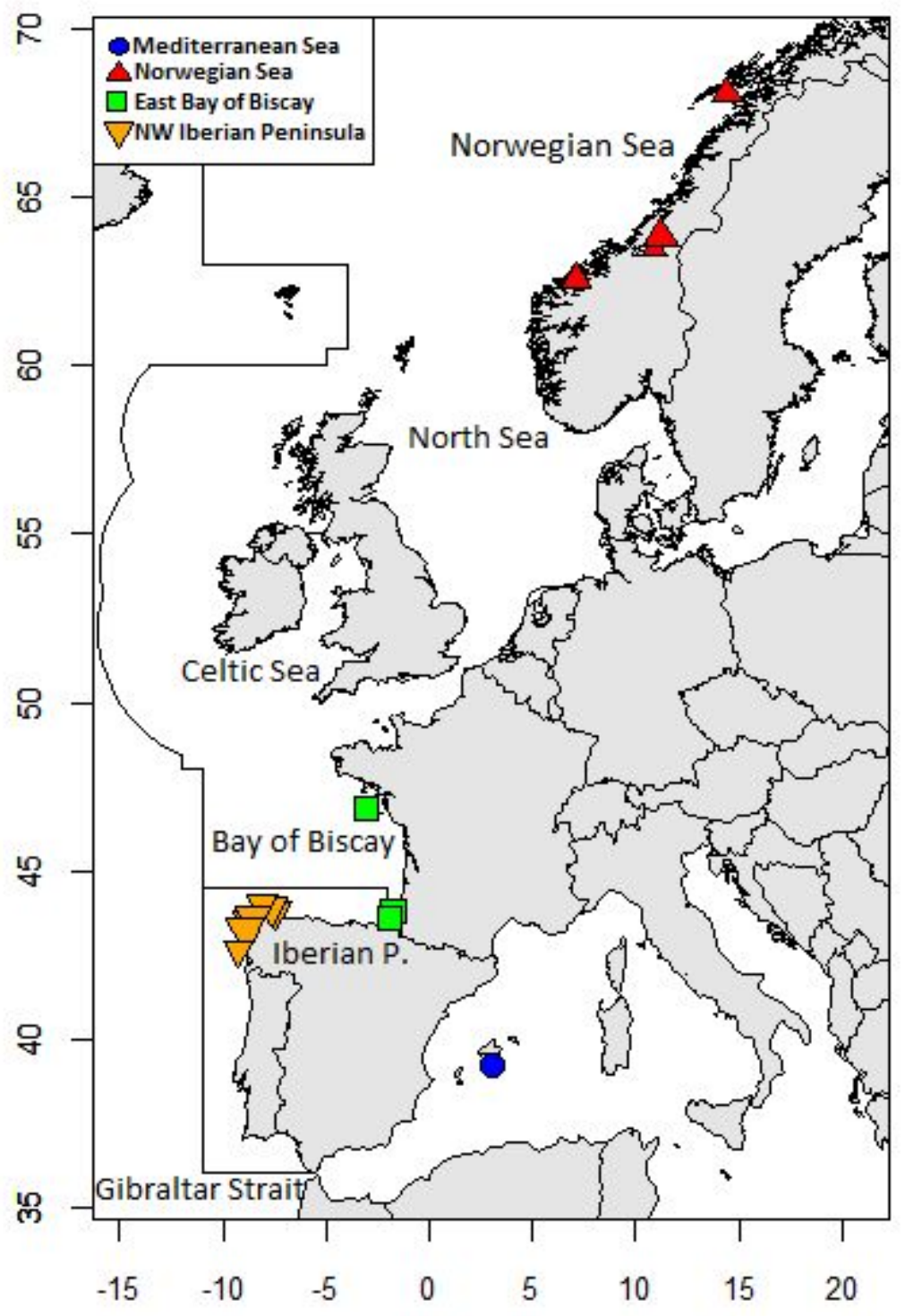

540

541

542 Figure 1: Sampling sites of European hake and ICES delimitation for the Northern (top) and Southern (bottom) stock management units. The border between Northern and

544 Southern stocks approximate the Capbreton Canyon. 

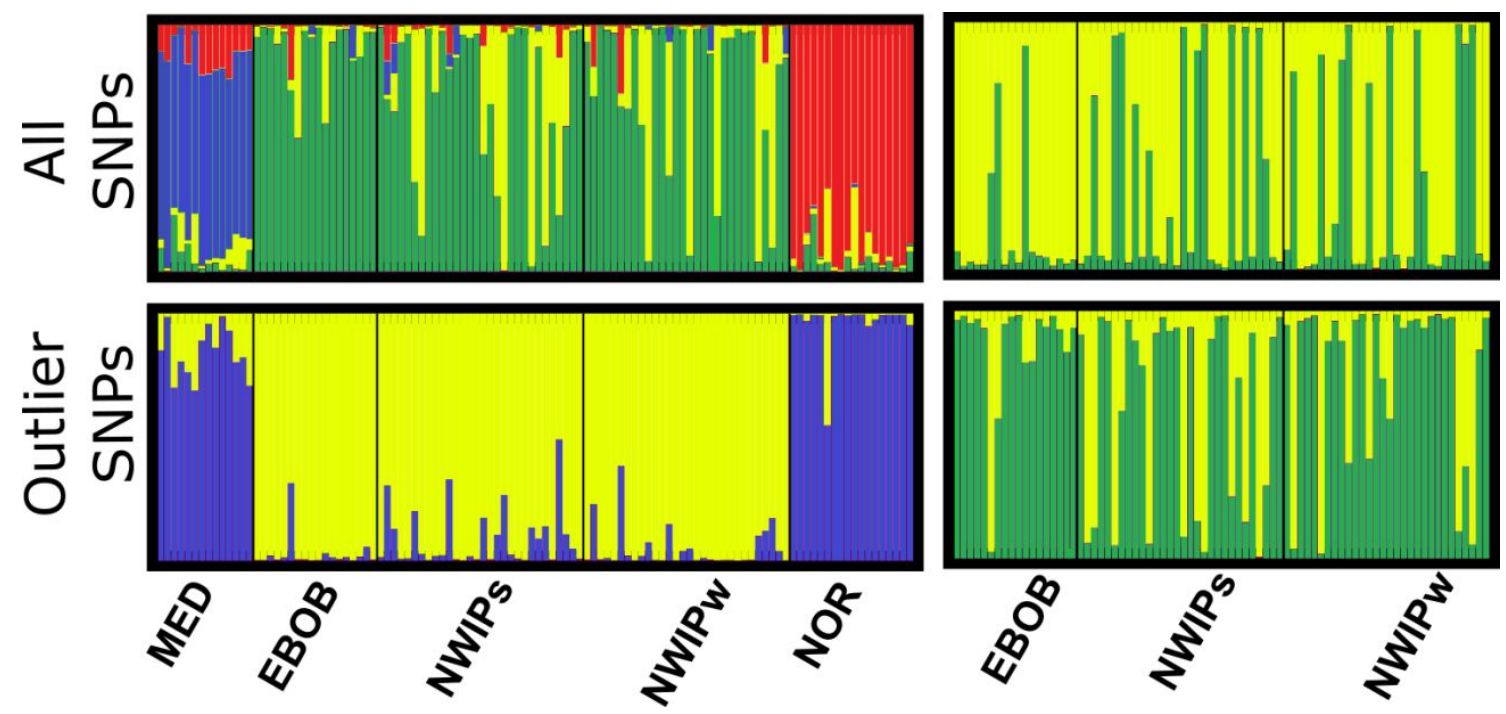

547

548 Figure 2: Graphical representation of the Bayesian clustering approach implemented in

549 STRUCTURE when using all (top) or only outlier SNPs (bottom) and all (left) or only the

550 Eastern Bay of Biscay and Northwestern Iberian Peninsula samples (right) for the best $\mathrm{K}$ 551 value according to the Evanno method, which is $\mathrm{K}=2$ for all dataset except for the all 552 SNPs all samples dataset, for which it is $\mathrm{K}=4$. Refer to Table 1 for location codes. 


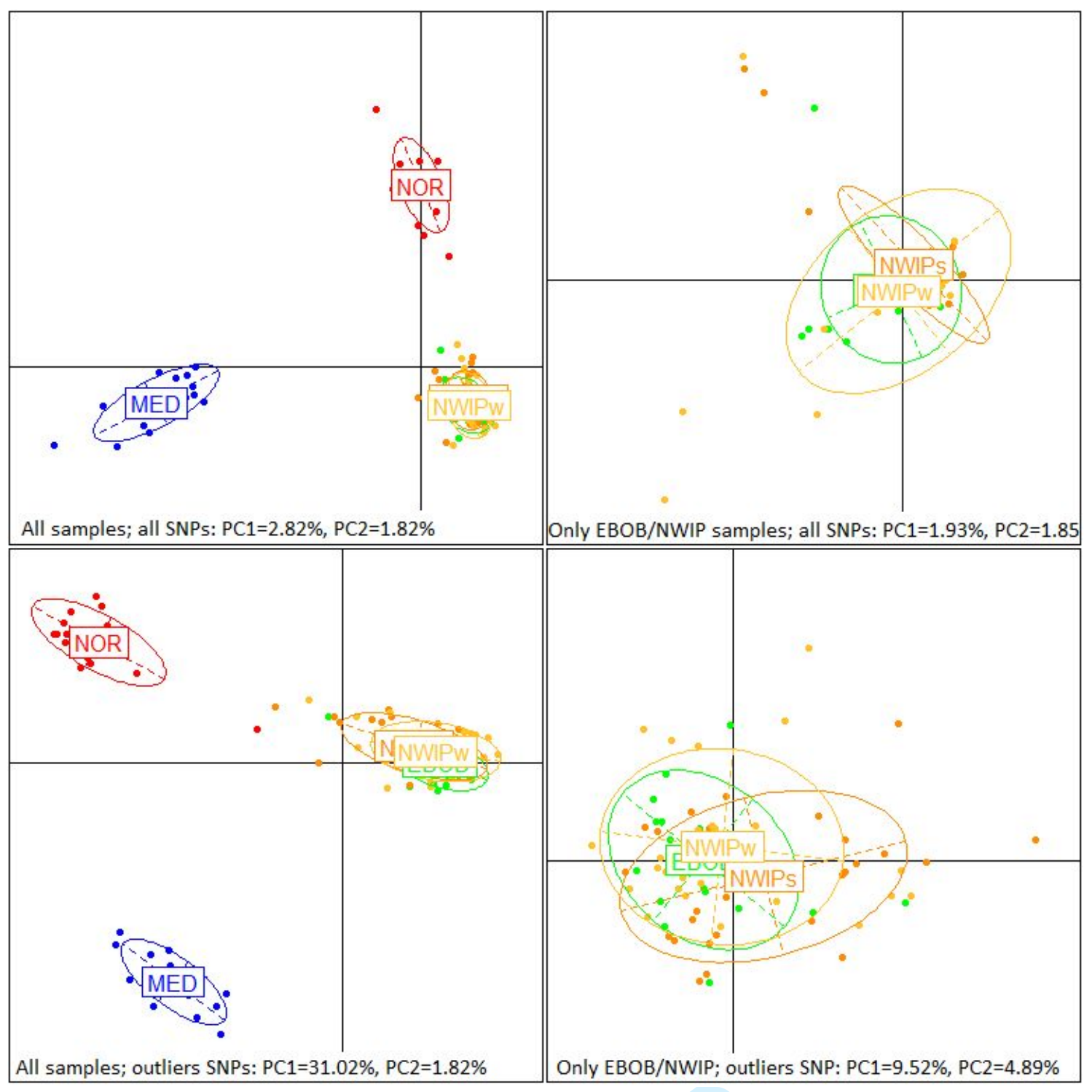

555

Figure 3: Principal Component Analysis (PCA) when using all (top) or only outlier SNPs

557 (bottom) and all (left) or only the Eastern Bay of Biscay and Northwestern Iberian 558 Peninsula samples (right). The variance explained by each axis of the PCA reflects the 559 amount of variation observed when using the total or the outlier SNPs dataset. 


\section{Leone et al.}

\section{Supplementary Tables}

Table S1: Samples used for this study and their associated metadata. In Sex column, 1 indicates male and 2, female; maturity stages are in Walsh scale

\begin{tabular}{|c|c|c|c|c|c|c|c|c|c|c|}
\hline SampleID & Area & Season & Stage & Lat & Long & $\begin{array}{l}\text { Size } \\
(\mathrm{mm})\end{array}$ & $\begin{array}{l}\text { Weight } \\
\text { (g) }\end{array}$ & Sex & $\begin{array}{l}\text { Maturity } \\
\text { stage }\end{array}$ & Catch Date \\
\hline CAN0016 & Eastern Bay of Biscay & Autumn & Adult & 43.57 & -1.90 & 724 & 2720.6 & 2 & 3 & $29 / 11 / 2016$ \\
\hline CAN0017 & Eastern Bay of Biscay & Spring & Adult & 43.57 & -1.90 & 725 & 2700 & 2 & 3 & $25 / 05 / 2016$ \\
\hline CAN0049 & Eastern Bay of Biscay & Spring & Adult & 43.71 & -1.69 & 610 & 1435 & 2 & 3 & $25 / 04 / 2016$ \\
\hline CAN0054 & Eastern Bay of Biscay & Spring & Adult & 43.57 & -1.90 & 680 & 2616 & 2 & 3 & $25 / 05 / 2016$ \\
\hline CAN0018 & Eastern Bay of Biscay & Winter & Adult & 43.57 & -1.90 & 620 & 1590.8 & 2 & 3 & $25 / 01 / 2017$ \\
\hline CAN0019 & Eastern Bay of Biscay & Winter & Adult & 43.57 & -1.90 & 668 & 2171 & 2 & 3 & $31 / 01 / 2017$ \\
\hline CAN0020 & Eastern Bay of Biscay & Winter & Adult & 43.57 & -1.90 & 670 & 2057 & 2 & 3 & $31 / 01 / 2017$ \\
\hline CAN0031 & Eastern Bay of Biscay & Winter & Adult & 43.57 & -1.90 & 623 & 1885.2 & 2 & 3 & $02 / 02 / 2017$ \\
\hline CAN0061 & Eastern Bay of Biscay & Winter & Adult & 43.57 & -1.90 & 698 & 2378 & 2 & 3 & $31 / 01 / 2017$ \\
\hline CAN0062 & Eastern Bay of Biscay & Winter & Adult & 43.57 & -1.90 & 621 & 1888 & 2 & 3 & $01 / 12 / 2016$ \\
\hline CAN0063 & Eastern Bay of Biscay & Winter & Adult & 43.57 & -1.90 & 694 & 2402 & 2 & 3 & $25 / 01 / 2017$ \\
\hline CAN0064 & Eastern Bay of Biscay & Winter & Adult & 43.57 & -1.90 & 608 & 1447.8 & 2 & 3 & $31 / 01 / 2017$ \\
\hline CAN0087 & Eastern Bay of Biscay & Winter & Adult & 43.57 & -1.90 & 660 & 1866 & 2 & 3 & $01 / 02 / 2017$ \\
\hline CAN0090 & Eastern Bay of Biscay & Winter & Adult & 43.57 & -1.90 & 648 & 2028.1 & 2 & 3 & $02 / 02 / 2017$ \\
\hline CAN0104 & Eastern Bay of Biscay & Winter & Adult & 43.57 & -1.90 & 592 & 1465 & 2 & 3 & $31 / 01 / 2017$ \\
\hline CAN0105 & Eastern Bay of Biscay & Winter & Adult & 46.83 & -3.00 & 910 & 5800 & 2 & 3 & $20 / 03 / 2016$ \\
\hline CAN0107 & Eastern Bay of Biscay & Winter & Adult & 43.57 & -1.90 & 641 & 1889.3 & 2 & 3 & $31 / 01 / 2017$ \\
\hline CAN0109 & Eastern Bay of Biscay & Winter & Adult & 43.57 & -1.90 & 800 & 3486 & 2 & 3 & $31 / 01 / 2017$ \\
\hline GaV0029 & Northwestern Iberian Peninsula & Summer & Adult & 43.25 & -9.10 & 534 & 1090 & 2 & 2 & $10 / 07 / 2017$ \\
\hline GaV0032 & Northwestern Iberian Peninsula & Summer & Adult & 43.25 & -9.10 & 523 & 1138 & 2 & 4 & $10 / 07 / 2017$ \\
\hline GaV0034 & Northwestern Iberian Peninsula & Summer & Adult & 43.25 & -9.10 & 559 & 1386 & 2 & 3 & $10 / 07 / 2017$ \\
\hline GaV0039 & Northwestern Iberian Peninsula & Summer & Adult & 43.25 & -9.10 & 532 & 1196 & 2 & 4 & 06/06/2017 \\
\hline GaV0041 & Northwestern Iberian Peninsula & Summer & Adult & 43.25 & -9.10 & 553 & 1284 & 2 & 2 & $10 / 07 / 2017$ \\
\hline GaV0046 & Northwestern Iberian Peninsula & Summer & Adult & 43.25 & -9.10 & 525 & 1146 & 2 & 2 & $10 / 07 / 2017$ \\
\hline GaV0053 & Northwestern Iberian Peninsula & Summer & Adult & 43.25 & -9.10 & 558 & 1252 & 2 & 4 & $04 / 07 / 2017$ \\
\hline GaV0058 & Northwestern Iberian Peninsula & Summer & Adult & 43.25 & -9.10 & 535 & 1180 & 2 & 2 & 06/06/2017 \\
\hline GaV0066 & Northwestern Iberian Peninsula & Summer & Adult & 43.25 & -9.10 & 515 & 988 & 2 & 2 & 06/06/2017 \\
\hline GaV0077 & Northwestern Iberian Peninsula & Summer & Adult & 43.25 & -9.10 & 544 & 1248 & 2 & 2 & 06/06/2017 \\
\hline GaV0085 & Northwestern Iberian Peninsula & Summer & Adult & 43.25 & -9.10 & 500 & 1172 & 2 & 4 & $10 / 07 / 2017$ \\
\hline GaV0094 & Northwestern Iberian Peninsula & Summer & Adult & 43.25 & -9.10 & 556 & 1354 & 2 & 2 & 06/06/2017 \\
\hline GaV0106 & Northwestern Iberian Peninsula & Summer & Adult & 43.25 & -9.10 & 531 & 1266 & 2 & 2 & $10 / 07 / 2017$ \\
\hline GaV0108 & Northwestern Iberian Peninsula & Summer & Adult & 43.25 & -9.10 & 514 & 1050 & 2 & 2 & 06/06/2017 \\
\hline GaV0110 & Northwestern Iberian Peninsula & Summer & Adult & 43.25 & -9.10 & 553 & 1290 & 2 & 2 & $06 / 06 / 2017$ \\
\hline GaV0021 & Northwestern Iberian Peninsula & Summer & Juvenile & 43.79 & -7.52 & 174 & N/A & N/A & N/A & $27 / 06 / 2017$ \\
\hline GaV0022 & Northwestern Iberian Peninsula & Summer & Juvenile & 43.79 & -7.51 & 157 & N/A & N/A & N/A & $27 / 06 / 2017$ \\
\hline GaV0023 & Northwestern Iberian Peninsula & Summer & Juvenile & 43.90 & -7.67 & 160 & N/A & N/A & N/A & $27 / 06 / 2017$ \\
\hline GaV0025 & Northwestern Iberian Peninsula & Summer & Juvenile & 43.79 & -7.52 & 176 & $\mathrm{~N} / \mathrm{A}$ & N/A & N/A & $27 / 06 / 2017$ \\
\hline GaV0027 & Northwestern Iberian Peninsula & Summer & Juvenile & 43.79 & -7.52 & 162 & N/A & N/A & N/A & $27 / 06 / 2017$ \\
\hline GaV0028 & Northwestern Iberian Peninsula & Summer & Juvenile & 43.89 & -7.81 & 160 & N/A & N/A & N/A & $27 / 06 / 2017$ \\
\hline GaV0074 & Northwestern Iberian Peninsula & Summer & Juvenile & 43.89 & -7.81 & 167 & N/A & $\mathrm{N} / \mathrm{A}$ & $\mathrm{N} / \mathrm{A}$ & $27 / 06 / 2017$ \\
\hline
\end{tabular}




\begin{tabular}{|c|c|c|c|c|c|c|c|c|c|c|}
\hline MED0009 & Mediterranean Sea & Autumn & Adult & 39.22 & 3.00 & 197 & 51.54 & N/A & N/A & $18 / 11 / 2016$ \\
\hline MED0010 & Mediterranean Sea & Autumn & Adult & 39.22 & 3.00 & 208 & 55.38 & N/A & N/A & $18 / 11 / 2016$ \\
\hline MED0011 & Mediterranean Sea & Autumn & Adult & 39.22 & 3.00 & 197 & 46.34 & N/A & N/A & $18 / 11 / 2016$ \\
\hline MED0012 & Mediterranean Sea & Autumn & Adult & 39.22 & 3.00 & 207 & 60.8 & N/A & N/A & $18 / 11 / 2016$ \\
\hline MED0013 & Mediterranean Sea & Autumn & Adult & 39.22 & 3.00 & 196 & 62.67 & N/A & N/A & $18 / 11 / 2016$ \\
\hline MED0014 & Mediterranean Sea & Autumn & Adult & 39.22 & 3.00 & 192 & 44.92 & N/A & N/A & $18 / 11 / 2016$ \\
\hline MED0015 & Mediterranean Sea & Autumn & Adult & 39.22 & 3.00 & 196 & 50.66 & N/A & N/A & $18 / 11 / 2016$ \\
\hline NOR0036 & Norwegian Sea & Autumn & Adult & 62.60 & 7.11 & 1050 & 530 & 2 & 3 & $02 / 11 / 2017$ \\
\hline NOR0040 & Norwegian Sea & Autumn & Adult & 62.60 & 7.11 & 1140 & 560 & 2 & 3 & $02 / 11 / 2017$ \\
\hline NOR0043 & Norwegian Sea & Autumn & Adult & 63.97 & 11.20 & 1480 & 580 & 2 & 3 & $30 / 10 / 2017$ \\
\hline NOR0044 & Norwegian Sea & Autumn & Adult & 68.12 & 14.41 & 4094 & 800 & 1 & 4 & $02 / 11 / 2017$ \\
\hline NOR0045 & Norwegian Sea & Autumn & Adult & 63.46 & 10.86 & 1915 & 660 & 2 & 4 & $31 / 10 / 2017$ \\
\hline NOR0048 & Norwegian Sea & Autumn & Adult & 68.12 & 14.41 & 6115 & 900 & 1 & 4 & $02 / 11 / 2017$ \\
\hline NOR0050 & Norwegian Sea & Autumn & Adult & 62.60 & 7.11 & 1875 & 630 & 2 & 3 & $02 / 11 / 2017$ \\
\hline NOR0051 & Norwegian Sea & Autumn & Adult & 62.60 & 7.11 & 2335 & 690 & 2 & 3 & $02 / 11 / 2017$ \\
\hline NOR0052 & Norwegian Sea & Autumn & Adult & 62.60 & 7.11 & 2085 & 680 & 1 & 4 & $02 / 11 / 2017$ \\
\hline NOR0055 & Norwegian Sea & Autumn & Adult & 63.78 & 11.32 & 5535 & 930 & 1 & 4 & $30 / 10 / 2017$ \\
\hline NOR0060 & Norwegian Sea & Autumn & Adult & 63.97 & 11.20 & 2450 & 680 & 2 & 3 & $30 / 10 / 2017$ \\
\hline NOR0069 & Norwegian Sea & Autumn & Adult & 63.79 & 11.37 & 2186 & 680 & 2 & 3 & $31 / 10 / 2017$ \\
\hline NOR0070 & Norwegian Sea & Autumn & Adult & 63.46 & 10.86 & 4615 & 850 & 1 & 4 & $31 / 10 / 2017$ \\
\hline NOR0072 & Norwegian Sea & Autumn & Adult & 62.60 & 7.11 & 2030 & 670 & 2 & 4 & $02 / 11 / 2017$ \\
\hline NOR0075 & Norwegian Sea & Autumn & Adult & 62.60 & 7.11 & 3085 & 730 & 2 & 4 & $02 / 11 / 2017$ \\
\hline NOR0086 & Norwegian Sea & Autumn & Adult & 63.46 & 10.86 & 5255 & 870 & 1 & 4 & $31 / 10 / 2017$ \\
\hline NOR0095 & Norwegian Sea & Autumn & Adult & 63.46 & 10.86 & 2070 & 640 & 2 & 4 & $31 / 10 / 2017$ \\
\hline NOR0102 & Norwegian Sea & Autumn & Adult & 63.97 & 11.20 & 1465 & 580 & 2 & 3 & $30 / 10 / 2017$ \\
\hline
\end{tabular}


Table S2: Results from mapping the flanking region of the outlier SNPs against the nonredundant database. Only the match with the lowest E-value is shown.

\begin{tabular}{|c|c|c|c|}
\hline SNP & Accession & Definition & E value \\
\hline 4525 & XM_022196154.1 & $\begin{array}{l}\text { PREDICTED: Acanthochromis polyacanthus } \\
\text { gap junction alpha-3 protein-like } \\
\text { (LOC110952557), mRNA }\end{array}$ & $9.02 e-119$ \\
\hline 4926 & XM_013030874.1 & $\begin{array}{l}\text { PREDICTED: Dipodomys ordii cytoplasmic } \\
\text { FMR1 interacting protein } 2 \text { (Cyfip2), mRNA }\end{array}$ & $2.19 e-35$ \\
\hline 6046 & XM_022760061.1 & $\begin{array}{l}\text { PREDICTED: Seriola dumerili protocadherin- } \\
11 \text { X-linked-like (LOC111232503), mRNA }\end{array}$ & 8.53e-159 \\
\hline 6190 & XM_021583880.1 & $\begin{array}{l}\text { PREDICTED: Oncorhynchus mykiss disks large } \\
\text { homolog 3-like (LOC110504964), mRNA }\end{array}$ & $1.73 e-21$ \\
\hline 7282 & LR584051.1 & $\begin{array}{l}\text { Echeneis naucrates genome assembly, } \\
\text { chromosome: } 10\end{array}$ & $1.76 \mathrm{e}-06$ \\
\hline 8086 & XM_028589501.1 & $\begin{array}{l}\text { PREDICTED: Perca flavescens family with } \\
\text { sequence similarity } 193 \text { member B } \\
\text { (fam193b), transcript variant X2, mRNA }\end{array}$ & $1.41 \mathrm{e}-72$ \\
\hline 8358 & FJ356236.1 & $\begin{array}{l}\text { Gadus morhua interferon gamma gene, } \\
\text { complete cds }\end{array}$ & $2.49 e-35$ \\
\hline 8380 & AC145509.2 & $\begin{array}{l}\text { Gasterosteus aculeatus clone } \mathrm{CH} 213-128017 \text {, } \\
\text { complete sequence }\end{array}$ & $6.96 e-31$ \\
\hline 8730 & СР032600.1 & $\begin{array}{l}\text { Lateolabrax maculatus linkage group } 3 \\
\text { sequence }\end{array}$ & $1.53 e-17$ \\
\hline 12175 & СР032601.1 & $\begin{array}{l}\text { Lateolabrax maculatus linkage group } 4 \\
\text { sequence }\end{array}$ & $2.52 e-25$ \\
\hline 13653 & XM_028584606.1 & $\begin{array}{l}\text { PREDICTED: Perca flavescens myosin heavy } \\
\text { chain, fast skeletal muscle-like } \\
\text { (LOC114559754), mRNA }\end{array}$ & $1.12 e-53$ \\
\hline 15080 & XM_028587403.1 & $\begin{array}{l}\text { PREDICTED: Perca flavescens DET1 and DDB1 } \\
\text { associated } 1 \text { (dda1), mRNA }\end{array}$ & $2.60 e-89$ \\
\hline 16396 & LR131939.1 & $\begin{array}{l}\text { Cottoperca gobio genome assembly, } \\
\text { chromosome: } 9\end{array}$ & $1.34 \mathrm{e}-12$ \\
\hline 16634 & XM_020653185.1 & $\begin{array}{l}\text { PREDICTED: Labrus bergylta } \\
\text { adenosylhomocysteinase (ahcy), mRNA }\end{array}$ & $7.48 e-65$ \\
\hline 18187 & LR535848.1 & $\begin{array}{l}\text { Mastacembelus armatus genome assembly, } \\
\text { chromosome: } 16\end{array}$ & $2.77 e-44$ \\
\hline
\end{tabular}




\begin{tabular}{|l|l|l|l|}
\hline 18439 & CP032588.1 & $\begin{array}{l}\text { Lateolabrax maculatus linkage group 14 } \\
\text { sequence }\end{array}$ & $5.99 \mathrm{e}-41$ \\
\hline 18447 & XM_021315672.1 & $\begin{array}{l}\text { PREDICTED: Fundulus heteroclitus } \\
\text { deoxyribodipyrimidine photo-lyase-like } \\
\text { (LOC105925179), mRNA }\end{array}$ & $2.85 \mathrm{e}-24$ \\
\hline 19723 & AM482911.2 & $\begin{array}{l}\text { Vitis vinifera contig VV78X039251.4, whole } \\
\text { genome shotgun sequence }\end{array}$ & $8.14 \mathrm{e}-05$ \\
\hline 19876 & XR_003281901.1 & $\begin{array}{l}\text { PREDICTED: Carassius auratus } \\
\text { uncharacterized LOC113080568 } \\
\text { (LOC113080568), ncRNA }\end{array}$ & $5.82 \mathrm{e}-61$ \\
\hline 20488 & LR584244.1 & $\begin{array}{l}\text { Takifugu rubripes genome assembly, } \\
\text { chromosome: } 14\end{array}$ & $3.71 \mathrm{e}-18$ \\
\hline 20717 & XM_023395945.1 & $\begin{array}{l}\text { PREDICTED: Seriola lalandi dorsalis glypican- } \\
\text { 4-like (LOC111646457), mRNA }\end{array}$ & $2.23 \mathrm{e}-15$ \\
\hline 21822 & LR584244.1 & $\begin{array}{l}\text { Takifugu rubripes genome assembly, } \\
\text { chromosome: } 14\end{array}$ & $1.71 \mathrm{e}-21$ \\
\hline 21958 & LR535850.1 & $\begin{array}{l}\text { Mastacembelus armatus genome assembly, } \\
\text { chromosome: 18 }\end{array}$ & $7.61 \mathrm{e}-40$ \\
\hline 21962 & LR131921.1 & $\begin{array}{l}\text { Cottoperca gobio genome assembly, } \\
\text { chromosome: 14 }\end{array}$ & $1.29 \mathrm{e}-27$ \\
\hline 23239 & LR131918.1 & $\begin{array}{l}\text { Cottoperca gobio genome assembly, } \\
\text { chromosome: 11 }\end{array}$ & $4.75 \mathrm{e}-12$ \\
\hline XM_027031460.1 & $\begin{array}{l}\text { PREDICTED: Electrophorus electricus } \\
\text { monocarboxylate transporter 8-like } \\
\text { (LOC113591097), mRNA }\end{array}$ & $1.33 \mathrm{e}-07$ \\
\hline
\end{tabular}


Table S3: Evanno statistics for the whole and outlier SNP only datasets when using all or only the eastern Bay of Biscay and the northwestern Iberian Peninsula samples; values corresponding best $\mathrm{K}$ value are underlined

\begin{tabular}{|c|c|c|c|c|c|c|}
\hline & K & $\begin{array}{l}\text { Mean } \\
\text { LnP(K) }\end{array}$ & $\begin{array}{l}\text { Stdev } \\
\text { LnP(K) }\end{array}$ & $\operatorname{Ln}^{\prime}(\mathrm{K})$ & |Ln"(K)| & DeltaK \\
\hline \multirow{6}{*}{$\begin{array}{l}\text { All SNPs, } \\
\text { all samples }\end{array}$} & 1 & -1163684 & 13.2 & NA & NA & NA \\
\hline & 2 & -1156679 & 141.65 & 7005.32 & 2783.34 & 19.65 \\
\hline & 3 & -1152457 & 122.94 & 4221.98 & 6810.52 & 55.39 \\
\hline & 4 & -1155045 & 567.79 & -2588.54 & 37513.34 & 66.07 \\
\hline & 5 & -1195147 & 50925.22 & -40101.88 & 69276.86 & 1.36 \\
\hline & 6 & -1165972 & 9190.08 & 29174.98 & NA & NA \\
\hline \multirow{6}{*}{$\begin{array}{l}\text { Outlier SNPs, } \\
\text { all samples }\end{array}$} & 1 & -13232 & 0.2588 & NA & NA & NA \\
\hline & 2 & -10659 & 0.6301 & 2572.3 & 1519 & 2410.8 \\
\hline & 3 & -9606 & 0.6797 & 1053.3 & 965.84 & 1420.97 \\
\hline & 4 & -9519 & 1.5287 & 87.46 & 56.24 & 36.79 \\
\hline & 5 & -9487 & 8.3415 & 31.22 & 57.34 & 6.87 \\
\hline & 6 & -9514 & 13.0903 & -26.12 & NA & NA \\
\hline \multirow{4}{*}{$\begin{array}{l}\text { All SNPs, } \\
\text { southern } \\
\text { samples }\end{array}$} & 1 & -866473 & 12.04 & NA & NA & NA \\
\hline & 2 & -868999 & 896.29 & -2525.1 & 11028.5 & 12.3 \\
\hline & 3 & -882552 & 3369.37 & -13553.6 & 20239 & 6 \\
\hline & 4 & -875867 & 2780.82 & 6685.4 & NA & NA \\
\hline \multirow{4}{*}{$\begin{array}{c}\text { Outlier SNPs, } \\
\text { southern } \\
\text { samples }\end{array}$} & 1 & -6727.78 & 0.21 & NA & NA & NA \\
\hline & 2 & -6496.5 & 0.98 & 231.27 & 276.47 & 280.71 \\
\hline & 3 & -6541.7 & 15.45 & -45.2 & 56.37 & 3.65 \\
\hline & 4 & -6530.53 & 51.99 & 11.16 & NA & NA \\
\hline
\end{tabular}


Table S4: Pairwise FST value matrix when using neutral SNPs dataset without the 116 shared outliers and the total SNPs dataset (below and above diagonal respectively). Values in bold are significant after Bonferroni correction for multiple testing.

$\begin{array}{llllll} & \text { MED } & \text { EBOB } & \text { NWIPS } & \text { NWIPw } & \text { NOR } \\ \text { MED } & / & 0.052 & \mathbf{0 . 0 4 8} & 0.049 & 0.058 \\ \text { EBOB } & \mathbf{0 . 0 3 7} & / & 0.008 & 0.005 & 0.025 \\ \text { NWIPs } & \mathbf{0 . 0 3 3} & 0 & / & 0.005 & \mathbf{0 . 0 2 3} \\ \text { NWIPW } & \mathbf{0 . 0 3 3} & 0 & 0 & / & 0.025 \\ \text { NOR } & \mathbf{0 . 0 4 2} & \mathbf{0 . 0 1 5} & \mathbf{0 . 0 1 4} & \mathbf{0 . 0 1 4} & /\end{array}$

Table S5: Pairwise FST value matrix when using all SNPs from only adult specimens. Values in bold are significant after Bonferroni correction for multiple testing.

\begin{tabular}{|c|c|c|c|c|c|}
\hline & MED & EBOB & NWIPS & NWIPW & NOR \\
\hline MED & L & & & & \\
\hline EBOB & $\underline{0.054}$ & L & & & \\
\hline NWIPs & 0.056 & $\underline{0}$ & $L$ & & \\
\hline NWIPW & 0.056 & $\underline{0}$ & $\underline{0}$ & $L$ & \\
\hline NOR & 0.061 & $\underline{0.026}$ & 0.028 & 0.026 & L \\
\hline
\end{tabular}




\section{Supplementary Figures}



Figure S1: Number of RAD-loci and SNPs in the catalog (TOTAL) and those retained at each filtering step. Note that because a single SNP per loci was selected for downstream analyses, the number of SNPs retained at the end of the process is equal to the number of RAD loci remaining aft her the HWE filtering step. 

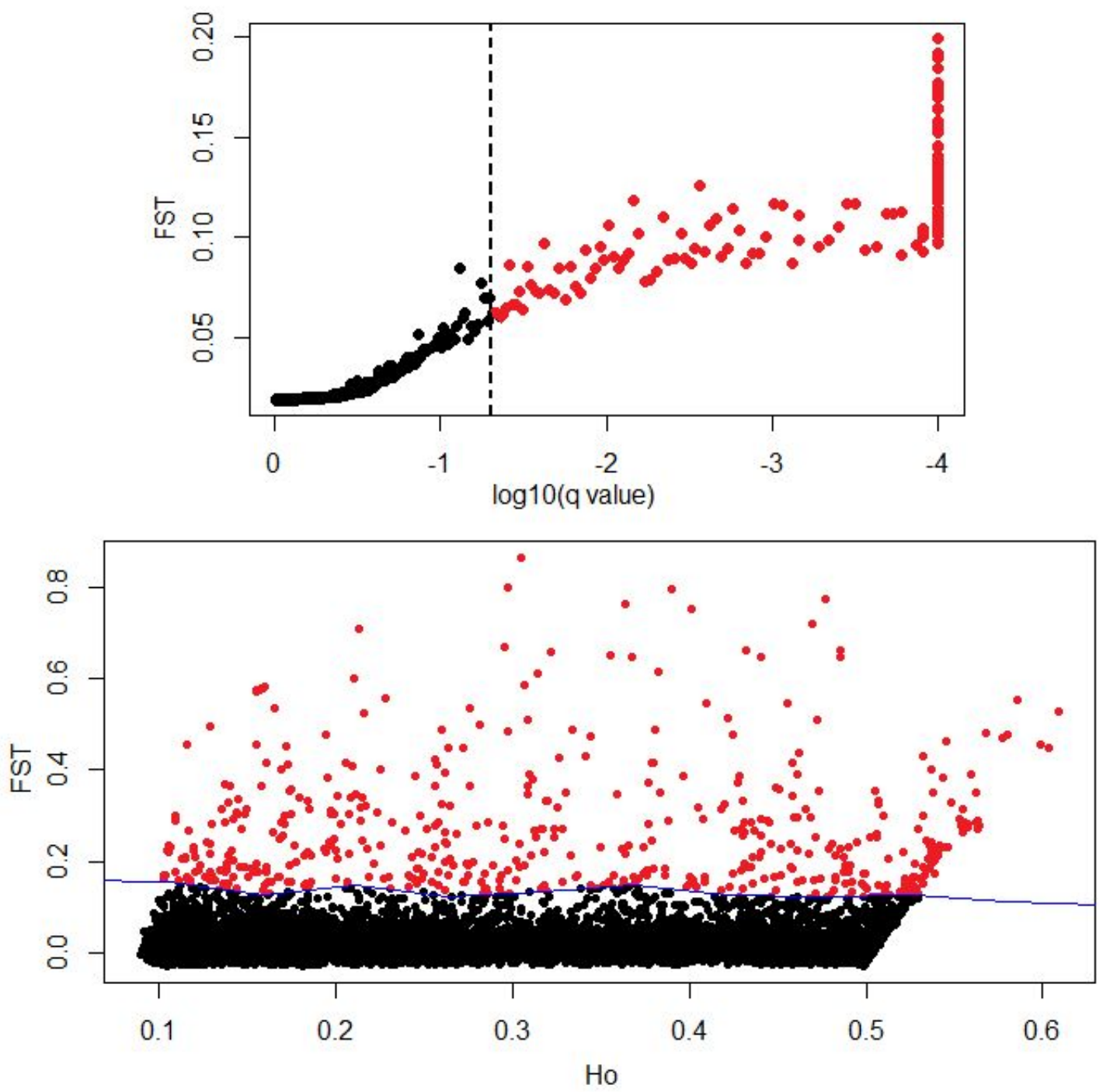

Figure S2: Results from the Bayesian scan for selection implemented in Bayescan, and the hierarchical model test for selection implemented in Arlequin. Bayescan outliers are defined as loci with q-value lower than 0.05 (in red), while Arlequin outliers are defined as loci that fall above the $99 \%$ quantile of the FST vs Observed Heterozygosity (in red). 

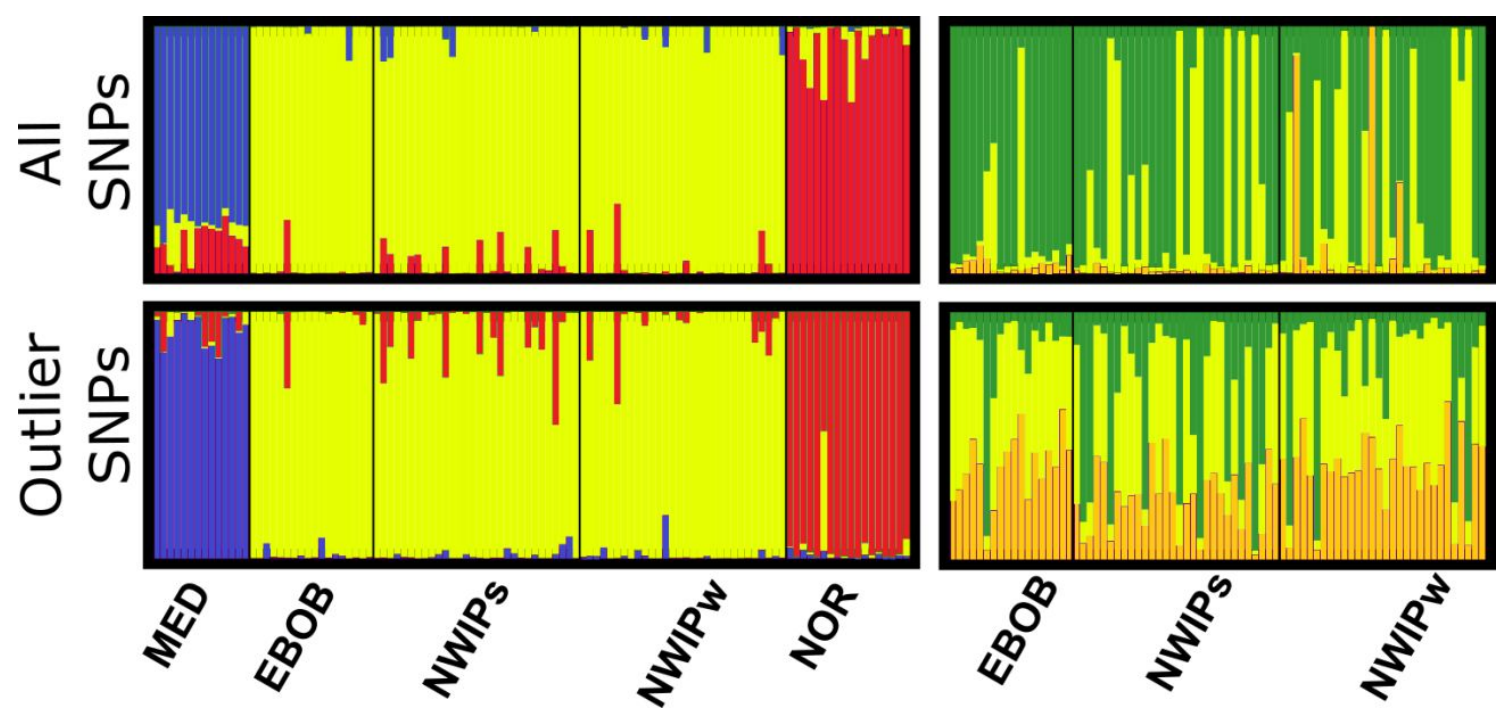

Figure S3: Graphical representation of the Bayesian clustering approach implemented in STRUCTURE when using all (top) or only outlier SNPs (bottom) and all (left) or only the Eastern Bay of Biscay and Northwestern Iberian Peninsula samples (right) for the second best $\mathrm{K}$ value according to the Evanno method, which is $\mathrm{K}=3$ for all cases. Refer to Table 1 for location codes. 

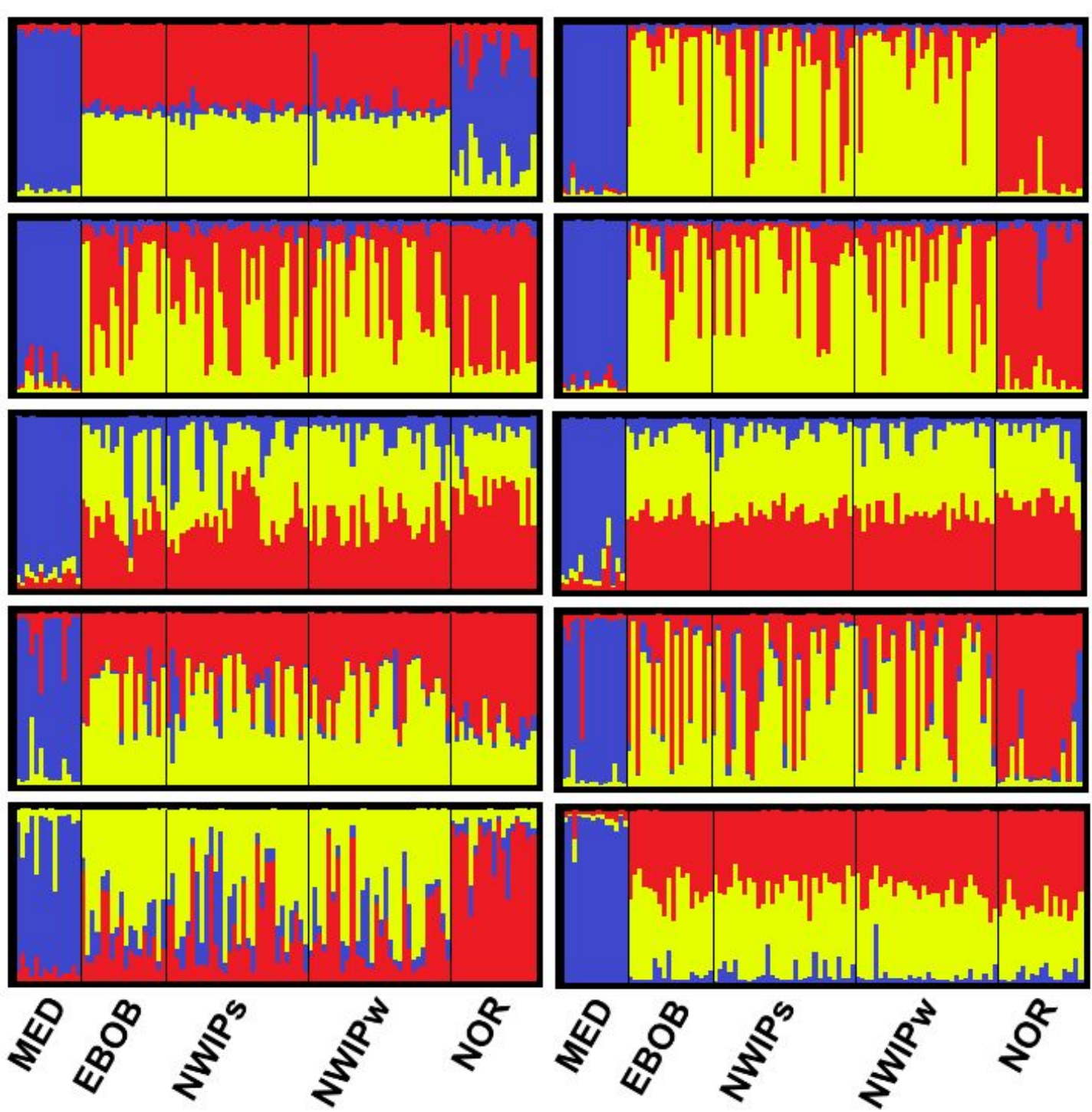

Figure S4: Graphical representation of the Bayesian clustering approach implemented in STRUCTURE when using 10 random subsets of 300 SNPs for $\mathrm{K}=3$. Refer to Table 1 for location codes. 


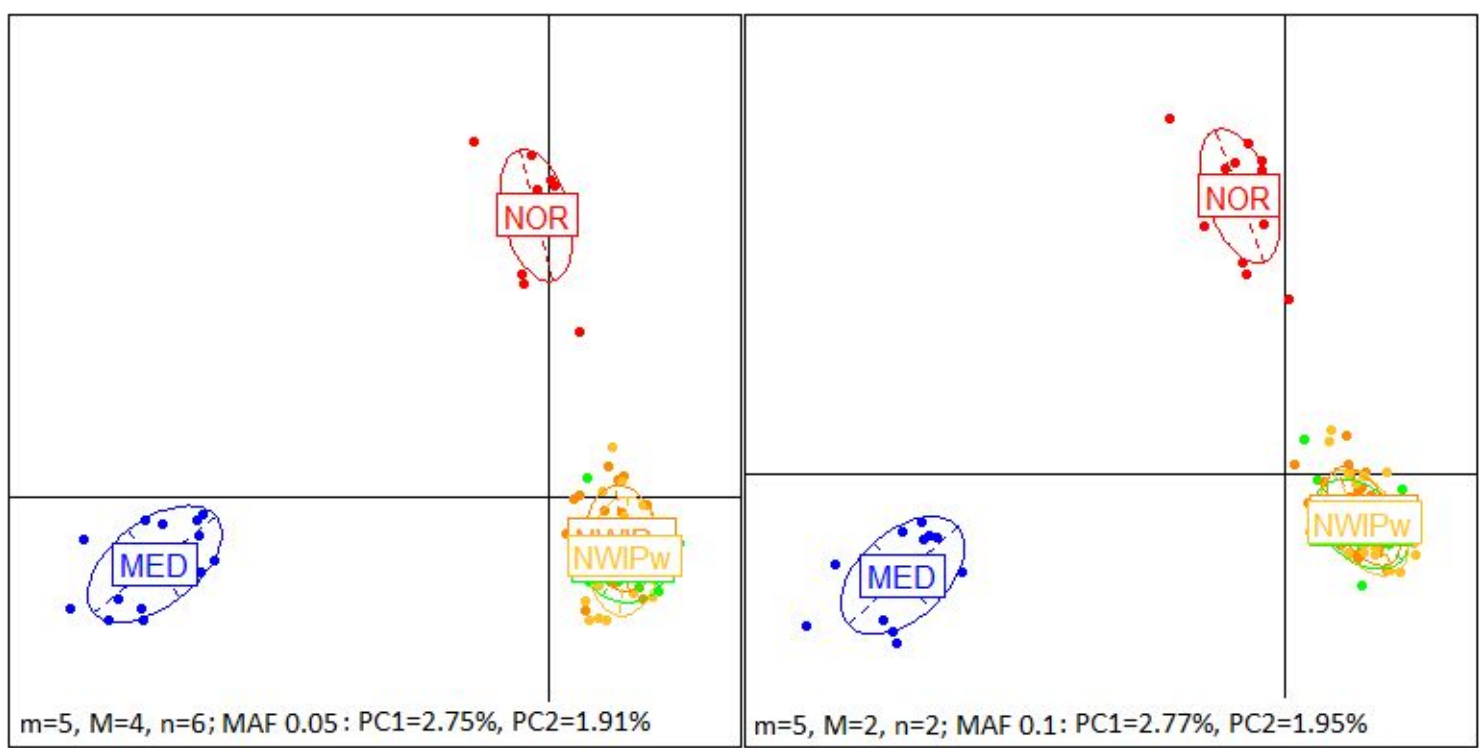

Figure S5: Principal Component Analysis (PCA) when using alternative RAD-tag assembly parameter values $(m=5, M=4, n=6)$, and an alternatives Minimum Allele Frequency (MAF) value threshold (0.1).

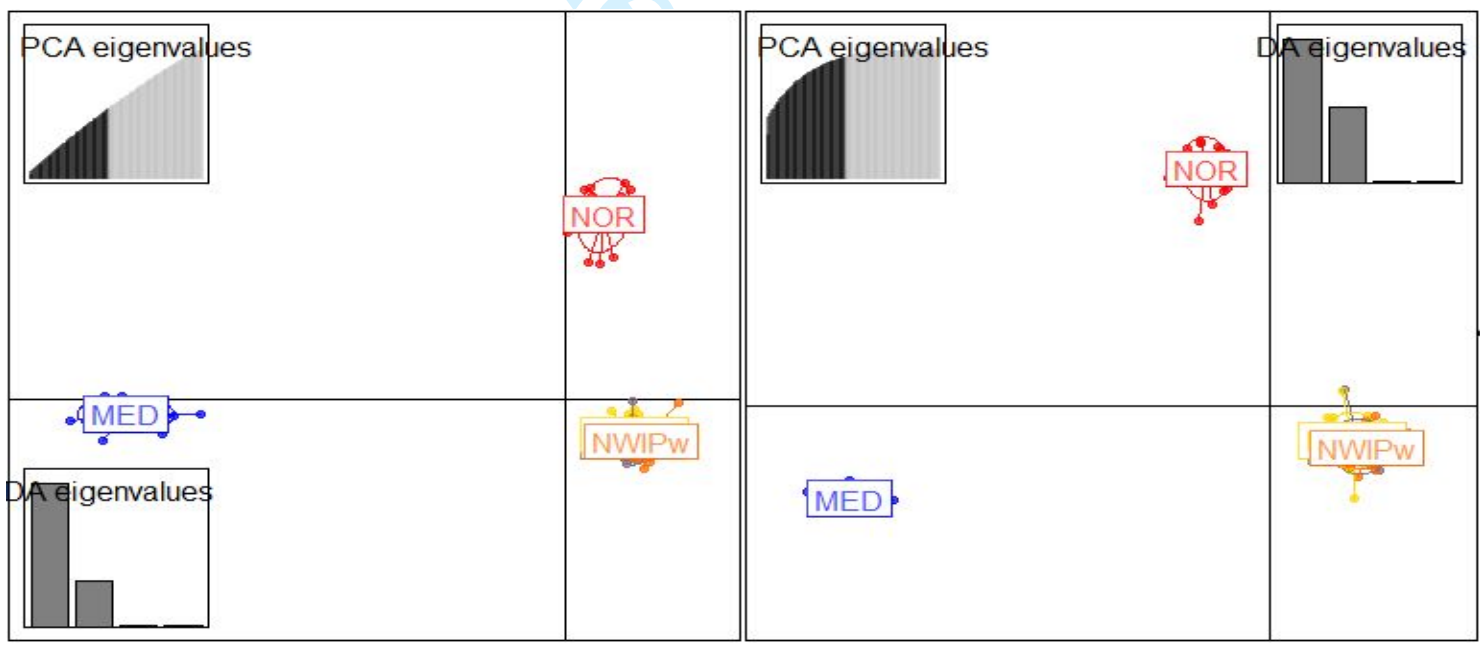

Figure S6: Discriminant Analysis of Principal Component (DAPC) for $\mathrm{K}=3$ using all 14120 SNPs (A), and the 116 outlier SNPs only (B). 


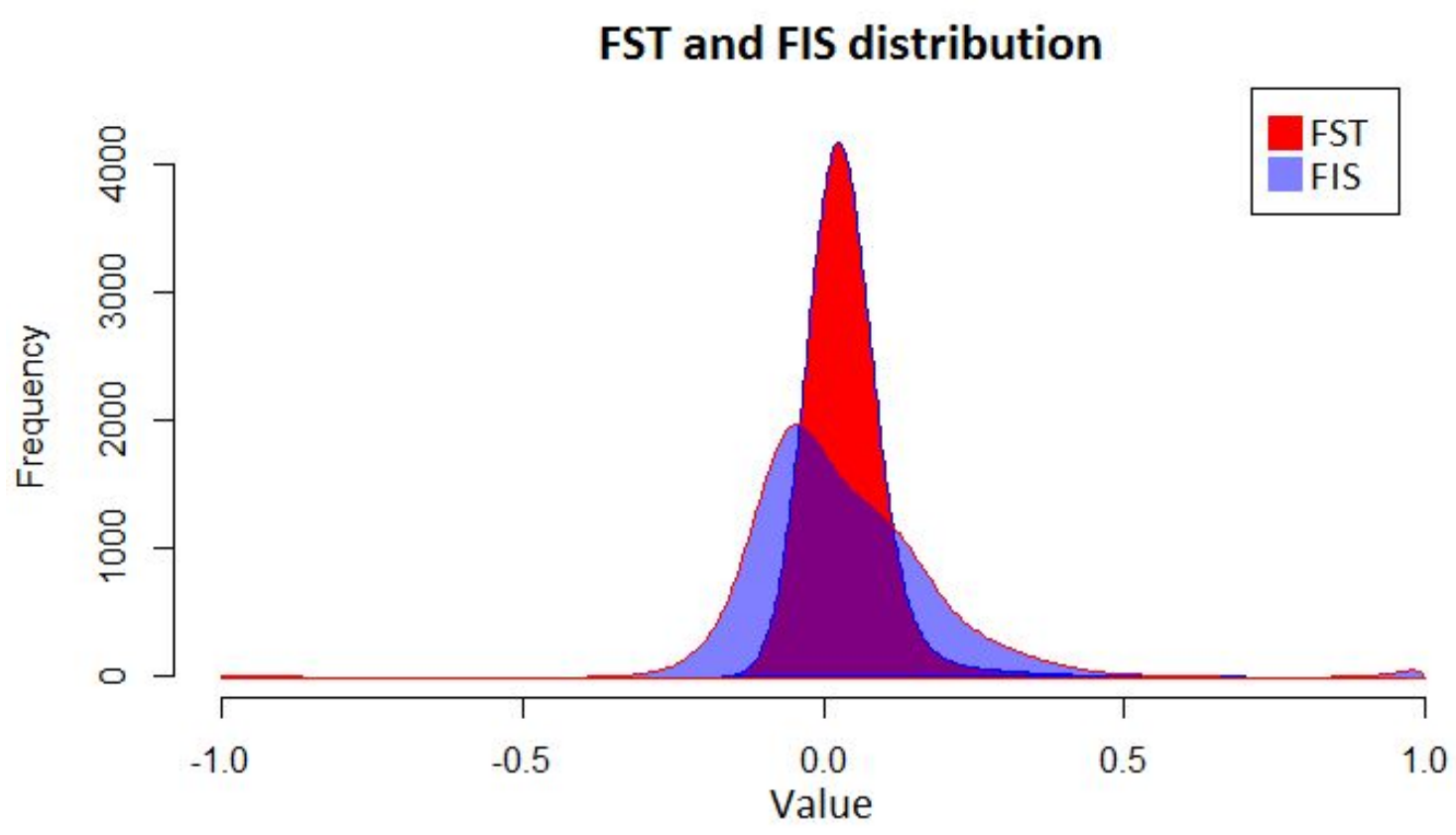

Figure S7: Distribution of FST and FIS values per SNP.

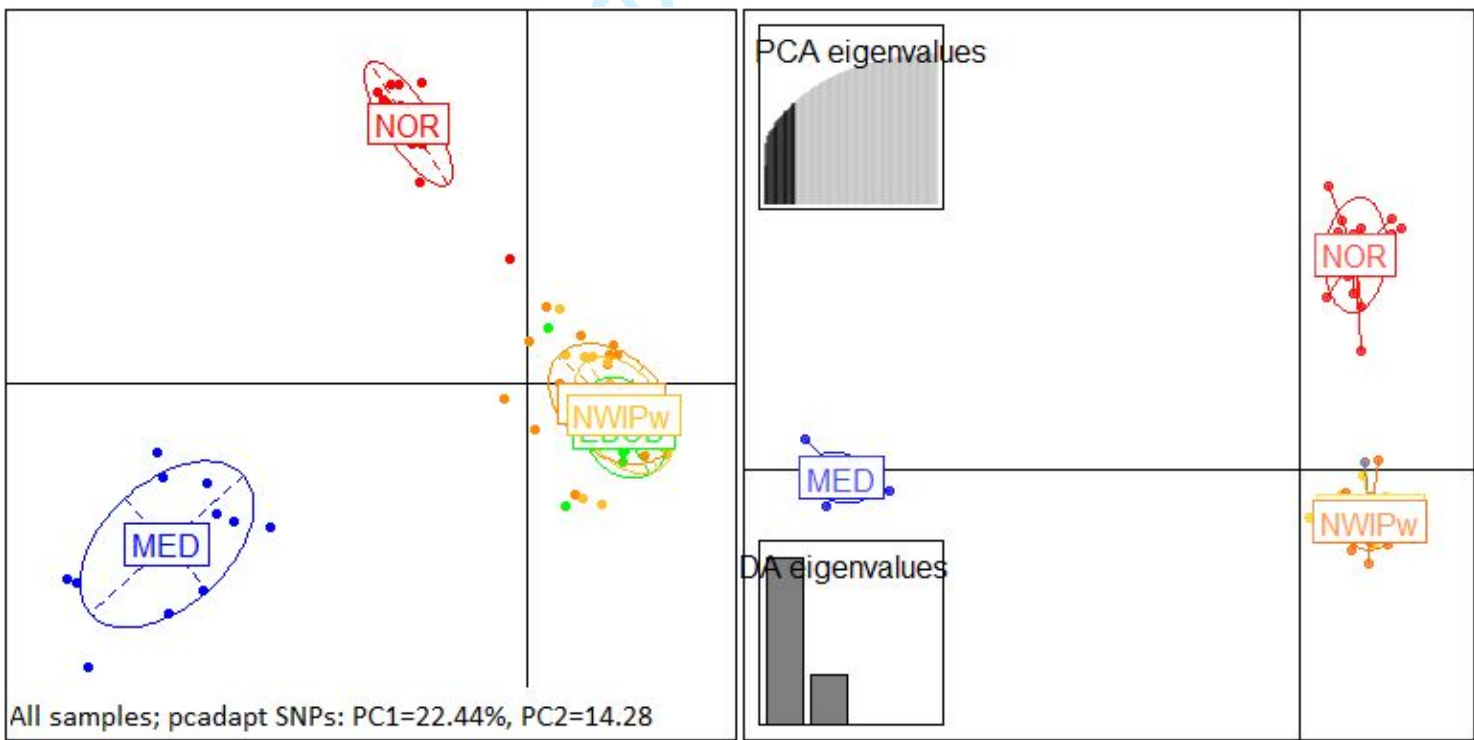

Figure 58: Principal Component Analysis (PCA), left, and Discriminant Analysis of Principal Component (DAPC), right, for $\mathrm{K}=3$ using 347 outlier SNPs selected by the multivariate approach implemented in pcadapt. 